\title{
Progress in interlaminar toughening of aerospace polymer composites using particles and non-woven veils
}

\author{
O. İnal ${ }^{1}$, K.B. Katnam ${ }^{2}$ (D) P. Potluri ${ }^{1}$ and C. Soutis ${ }^{1}$ \\ ${ }^{1}$ Department of Materials, The University of Manchester, Manchester, UK and ${ }^{2}$ Department of Mechanical, Aerospace and \\ Civil Engineering, The University of Manchester, Manchester, UK \\ E-mail: Kali-Babu.Katnam@manchester.ac.uk
}

Received: 6 July 2021; Revised: 9 September 2021; Accepted: 27 September 2021

Keywords: Composite laminates; Damage tolerance; Delamination; Interlaminar fracture toughness; Multi-scale toughening; Particle fillers; Non-woven fibre veils

\begin{abstract}
Fibre-reinforced polymer (FRP) composites generally have a layered architecture and are commonly manufactured with thermosetting resins-making them susceptible to interlaminar fracture (i.e. delamination), which is often a major concern in structurally critical applications. As a result, various approaches have been explored to enhance interlaminar fracture resistance. This review focuses on third-phase toughener inclusions, which offer opportunities to create damage resistant and damage tolerant structures without significantly adding weight or reducing in-plane mechanical properties. These toughener inclusions, typically introduced in the interlaminar regions, are divided into two categories herein: particle fillers and non-woven fibre veils. The advantages and limitations of both types are discussed, and the potential of the two approaches is evaluated using published data, aiming to provide an overview of the current understanding and challenges in designing and manufacturing safe and reliable composite structures.
\end{abstract}

\section{Nomenclature}

$$
\begin{aligned}
& G_{I, C} \\
& G_{I I, C} \\
& G_{I, R} \\
& \frac{G_{I I, R}}{G_{I, C}} \\
& G_{I I, C}
\end{aligned}
$$

$\begin{array}{ll}\text { Abbreviations } & \\ \text { FRP } & \text { Fibre-reinforced polymer } \\ \text { RTM } & \text { Resin transfer moulding } \\ \text { VARI } & \text { Vacuum-assisted resin infusion } \\ \text { CNF } & \text { Carbon nanofibre } \\ \text { CNT } & \text { Carbon nanotube } \\ \text { PPS } & \text { Polyphenylene sulfide } \\ \text { GNP } & \text { Graphene nanoplatelet } \\ \text { PSF } & \text { Polysulfone } \\ \text { PA } & \text { Polyamide } \\ \text { P(St-co-GMA) } & \text { Polystyrene-co-glycidyl methacrylate } \\ \text { PAN } & \text { Polyacrylonitrile } \\ \text { PP } & \text { Polypropylene } \\ \text { PET } & \text { Polyethylene terephthalate }\end{array}$

( 1 The Author(s), 2021. Published by Cambridge University Press on behalf of Royal Aeronautical Society. This is an Open Access article, distributed under the terms of the Creative Commons Attribution licence (http://creativecommons.org/licenses/by/4.0/), which permits unrestricted re-use, distribution, and reproduction in any medium, provided the original work is properly cited.
Fracture toughness/energy in mode-I crack initiation/onset

Fracture toughness/energy in mode-II crack initiation/onset

Fracture toughness/energy in mode-I crack propagation

Fracture toughness/energy in mode-II crack propagation

The averaged value of fracture toughness/energy in mode-I fracture

The averaged value of fracture toughness/energy in mode-II fracture 


\subsection{Introduction}

Advanced fibre-reinforced polymer composite laminates are increasingly finding use in various industrial applications that demand superior mechanical properties together with weight-saving and long-term durability (e.g. aerospace and automotive structural components). However, composite laminates are generally susceptible to interlaminar cracking or delamination, which may initiate from various sources such as joints, ply drop-offs, skin-core interaction in sandwich structures, notches and in-service impact events [1-5]. Delamination can significantly reduce laminate strength and stiffness and can subsequently lead to premature catastrophic failure if undetected. Therefore, a significant amount of research has been conducted over the years to suppress and/or delay delamination initiation and propagation by improving the interlaminar fracture toughness of composite laminates.

The majority of composite laminates used in aerospace structures are currently thermoset based because of their high specific stiffness, high specific strength, durability and processability. But thermoset resins suffer from low fracture toughness because of inherent brittleness caused by high crosslinking density. Improving the fracture toughness and ductility of thermoset matrix composites is thus of paramount importance to enhance damage tolerance, extend service life, decrease knockdown factors in design, reduce maintenance and repair costs. However, the improvement in fracture toughness is often a trade-off between toughness and strength and/or manufacturability [6]. In this regard, various methods are explored to enhance delamination resistance in recent years. Extrinsic approaches such as Z-pins, stitching and 3D interlocking have been successfully applied [7-9]. None of these approaches seems to alter the inherent fracture toughness of composite laminates but rather inhibit crack growth via through-thickness reinforcement (i.e. pins or fibres). As a result, the in-plane fibres may be displaced (creating resin-rich areas) or even be damaged during the through-thickness insertion process, which may adversely affect strength and stiffness. Moreover, specialised equipment and additional fabrication steps are required to insert such through-thickness reinforcement. In contrast, third-phase materials such as particle fillers and non-woven veils (and their combinations), i.e. for multiscale toughening, are explored as an intrinsic approach to enhance toughness by introducing energy absorbing/dissipating phenomena (i.e. toughening mechanisms), at the same time avoiding in-plane fibre distortion and damage [10-13]. While the utilisation of non-woven veils is straightforward (by inserting between laminae during layup), particle tougheners are versatile and can be used in the form of particle blended resins, coatings, dissolvable interleaves, non-dissolvable particle interleaves or directly-growing/grafting on fibre surfaces-depending on the type of particles and process used.

A toughening system should ideally be cost-effective, easy-to-process without considerably degrading engineering properties such as mechanical, electrical and thermal properties. In addition, toughening routes compatible with out-of-autoclave processing methods, e.g. resin transfer moulding (RTM) and vacuum-assisted resin infusion (VARI), play a major role in cost-effective composite manufacturing $[12,14]$. In this context, this review aims to highlight and discuss particle and non-woven veil based toughening routes by focusing on the experimental studies published in recent years. The aspects of manufacturability and pros/cons of particle and non-woven veil toughening routes are presented and compared. Multi-scale toughening routes with various combinations of nano and micro-particles and non-woven veils are also discussed. The advantages, limitations and potential of both toughening routes are reviewed, while aiming to provide an overview of the current understanding and challenges in designing and manufacturing safe and reliable composite structures.

\subsection{Particle fillers for interlaminar toughening}

A wide variety of nano- and micro-scale particle fillers has been employed to improve the fracture behaviour of inherently brittle thermoset resins and their composite laminates [13, 15-23]. In this review, the term 'particle' refers to the toughening phase. These particles can either be introduced (predetermined size and shape) or be formed via phase-separation of dissolvable toughener materials. The manufacturing of particle toughened composite laminates are broadly divided into three types: 
(a) particle blended/dissolved resins to directly infuse or impregnate fibre preforms to produce a particledispersed matrix phase; (b) particle interleaving to introduce particles between neighbouring laminae by sifting, particle filtering, spraying or inserting dissolvable interleaves to form particulate morphology upon phase-separation; and (c) sizing/coating or particle-growing/grafting on reinforcement fibres. These approaches are presented by referring to the particles of rubber, nano-silica, thermoplastics, and carbon-based nanomaterials, i.e. graphene, carbon nanofibres (CNF) and carbon nanotubes (CNT).

Rubber particles, which can be either introduced via phase-separation during cure (i.e. reactive liquid rubber) or resin blend of predetermined size and morphology (e.g. core-shell rubber), have been employed for toughening thermoset matrix composites for several decades [24, 25]. Although rubber particles enhance toughness, it is observed that rubber particle content could adversely affect matrix stiffness, strength and glass transition temperature $\left(T_{g}\right)$. An additional rigid phase may thus be introduced to compensate for the property loss caused by rubber particle tougheners. For example, hybrid rubber and nano-silica particles have been explored and shown that the stiffness, strength and $T_{g}$ of composites can be retained [26-29]. The particle modified resin viscosity levels have been observed to be suitable for liquid resin processing and offer enhanced fracture toughness without significant loss in other desired mechanical properties [16, 30-34]. Moreover, the fracture toughness enhancement has been observed to be synergistic with hybrid particle blends [30]. But it should be taken into account that several studies have shown that high toughening often comes with relatively high particle content. Furthermore, high particle content often leads to high resin viscosity and subsequently results in non-uniform particle dispersion and agglomeration. However, the particle blended resin can be heated and transferred into a pre-heated tool to achieve low viscosity levels to overcome processing difficulties. When a particleblended resin is infused without particle agglomeration into a fibre preform, the toughening effect is often established not only in interlaminar regions but also in intralaminar regions (i.e. within laminae) if the particle size is sufficiently small compared to the inter-fibre distance. These particles do not increase laminate thickness as in interleaving methods. As an alternative to the particle blended resins, some of the manufacturing difficulties can be mitigated with particle coated/sized fibre preforms. For instance, nano-silica particles can be used to coat/size primary fibres to enhance fibre-matrix adhesion and, subsequently, fracture properties. With this approach, significant fracture energy improvements can be obtained using low particle content (i.e. below $1 \% \mathrm{wt}$ ). In contrast, matrix toughening requires an order of magnitude of particle content to achieve the same effect (i.e. about 10\%wt) [35]. However, maintaining the even distribution of the particles during the fibre coating process can be a major factor.

Thermoplastic tougheners (e.g. particles, coatings, films or dissolvable non-woven veils) can dissolve in thermoset resins, or soften and partially dissolve, or remain intact during manufacturing, depending on the compatibility between the thermoplastic and thermoset combined and the cure conditions employed $[12,18,36]$. Depending on the content of the thermoplastic phase, the dissolved thermoplastic can lead to phase-separation, co-continuous morphology or phase-inversion upon curing the thermoset [37, 38]. Undissolved thermoplastics remain as a discrete phase in the interlaminar regions [39]. Thermoplastic particles, in particular, are employed for toughening prepreg systems, which are successfully commercialised and used in aerospace structures [40-42]. Thermoplastic particles can be deposited on prepreg surfaces by sifting [37, 39] or filtration during impregnation [43]. Uniform particle distribution and particle-matrix compatibility are of crucial importance for both dispersed particles and phase-separated particles $[44,45]$. Thermoplastic coating on primary fibres can provide adequate toughener distribution in the interlaminar region but can lead to reduced compressibility and poor laminate consolidation. Additional external pressure should thus be required to achieve desired laminate compaction and fibre volume fractions [46]. Alternatively, dissolvable thermoplastic films can be used for interlaminar toughening. This method can be challenging with the liquid resin processing methods as the continuous film may barricade the resin flow in the through-the-thickness direction [12]. Film interleaving can be applied for prepregs as resin flow distances are small compared to resin infusion. The melted thermoplastic film may diffuse through reinforcement fibres of neighbouring fibre preform or prepreg laminae upon the application of heat and pressure, which could partially toughen the intralaminar regions in addition to 
the interlaminar region [42, 47]. Furthermore, thermoplastic non-woven veils can be used for interlaminar toughening (i.e. interleaves made of either dissolvable or undissolvable thermoplastic fibres), which are discussed in Section 3. For all the types of thermoplastic tougheners, the processing/manufacturing parameters and the thermoplastic precursor employed to produce the toughener can have a significant influence on the final particle morphology and resulting fracture properties [12, 40-42, 48].

Another category of particles that are considered for enhancing crack resistance and tolerance is carbon-based nanomaterials such as carbon black particles [49], carbon nanotubes (CNT) [50-52], carbon nanofibres (CNF) [53], and graphene-derivatives [52, 54-57], which have received increasing attention for a variety of engineering applications [58]. The superior mechanical properties of such novel materials are particularly attractive to enhance the mechanical properties and the interlaminar fracture toughness of composite laminates [59]. A low particle content (1-2\%) of carbon nano-materials often results in significant enhancements; in contrast, with higher particle content ( $>5 \% \mathrm{wt})$, the particles tend to agglomerate and significantly increase the resin viscosity. Thus, it becomes practically challenging to utilise liquid resin processing methods to infuse carbon nano-modified resins [60, 61]. Agglomeration of particles in the laminate, uneven particle distribution, and particle filtering by manufacturing consumables or fibres can lead to varying fracture toughness values at the interlaminar regions or even degrade fracture properties $[53,60,62]$. Thus, alternative techniques are needed to apply carbon nanofillers for interlaminar toughening. For example, techniques such as manual brushing and rolling can be used to adequately wet all the layers [50, 63, 64], although such manual methods may not be feasible for manufacturing large scale composite structural components. In addition, spraying a carbon nanomodified solution to coat individual lamina can aid the even particle distribution. The solvent in the spray solution must be evaporated before curing to prevent solvent entrapment, which could cause void formation [65]. CNT and CNF can be directly grown on the primary fibres [66, 67]. Grown-on or coated particles may reduce the laminate compressibility and compaction levels, requiring additional external pressure to achieve desired fibre volume fractions and laminate thickness [68, 69]. Alternatively, carbonnanomaterials can be deposited on/in carriers such as resin films [70] or non-woven veils [71, 72], then later be introduced at the interlaminar regions. Similarly, vertically aligned CNT arrays (forests) [73, 74], CNT sheets (synthesised with floating-catalyst chemical vapour deposition method) [75, 76], and bucky papers (made of CNFs or CNTs) [77, 78] can be interleaved at the interlaminar regions. Depending on the method used to manufacture carbon nano-toughened composite laminates, the toughening effect can exist not only at the interlaminar regions but also at the intralaminar regions (i.e. when primary fibres are successfully impregnated/coated with carbon nano-modified matrix, rather than depositing carbon nano-fillers at the interlaminar region).

\subsection{Non-woven veils for interlaminar toughening}

Non-woven veils, which are also referred to as mats, membranes or tissues, are fibrous networks (webs) composed of continuous or discontinuous (i.e. short/chopped) fibres, see Fig. 1(a). When introduced (i.e. interleaved) between neighbouring laminae during laminate stacking, interleaving fibres are located parallel to the laminate plane in the interlaminar regions. It can be thought of as sandwiching a discrete layer of fibres between primary laminae. Although non-woven veil interleaving is not a new idea $[79,80]$, this concept is reawakened lately due to several reasons: the properties of resin matrix (i.e. viscosity, glass transition temperature, strength and stiffness) are largely preserved [81-85], non-woven veils allow resin flow between neighbouring laminae because of their highly porous/permeable nature [86] (i.e. high compatibility with both prepreg and liquid resin processing methods [12, 87]). Additionally, non-woven veil interleaving significantly improves interlaminar fracture toughness without requiring considerable modifications to the manufacturing process, equipment or steps.

Non-woven veils can be broadly categorised into two groups: microfibre veils and nanofibre veils. Non-woven microfibre veils are made of randomly distributed short microfibres (i.e. a few microns in diameter), providing a high aspect ratio and high specific surface area. Microfibre veils are massproducible [88], and a wide variety of areal weights are commercially available, which ranges from as 
(a)

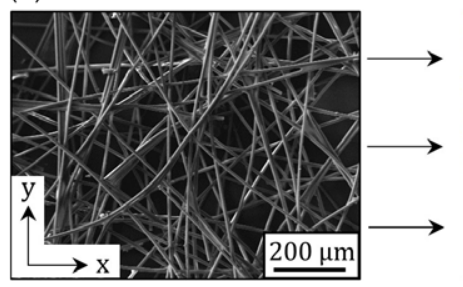

(b)

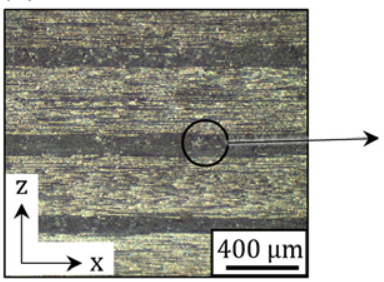

(c)

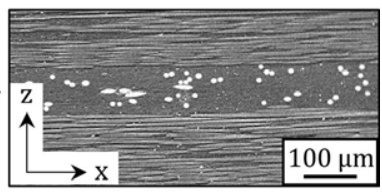

Figure 1. (a) SEM micrograph of a PPS (polyphenylene sulfide) microfibre non-woven veil, (b) cross-sectional optical and (c) SEM micrographs of carbon fibre-epoxy laminate interleaved with PPS non-woven microfibre veils (the $x, y$ and z-axes represent fibre, transverse and through-thickness directions, respectively).

light as a few grams to a couple of hundreds of grams per square meter (i.e. 2-400gsm) [89]. Various microfibres including thermoplastic fibres [83, 90-95], carbon [96], glass [97], aramid/Kevlar fibres $[98,99]$, and mixed blends of different fibres $[95,100]$ can be used for manufacturing veils. Microfibre veils have received particular attention for significant enhancements in mode-I [82, 90-92, 95, 101], mode-II [92, 100, 102] fracture toughness and the impact and post-impact performance of laminates [103, 104], together with cost-effectiveness and processability. But one of the drawbacks of microfibre veil interleaving is the inevitable increase in laminate thickness, especially when every interlaminar region is interleaved (see Fig. 1(b) and (c)). The thickness of the veil interleaved interlaminar region increases with the increased areal weight $[90,91,93]$. Although such an increase in thickness is observed to be beneficial for resisting impact loading $[11,105,106]$, it reduces the overall fibre volume fraction of the reinforcement fibres considerably in the laminate, affecting in-plane laminate strength and stiffness [93]. When non-woven veils with low areal weight are interleaved, laminate thickness (i.e. using constant thickness closed moulds) can be controlled for maintaining the in-plane properties [94]. Moreover, when pre-pregs are interleaved with microfibre veils, the resin contained by the prepreg layers may not be sufficient to fully wet/impregnate relatively thick veils (i.e. high areal weight), which can lead to void generation and affect the laminate properties [96]. Such a problem is unlikely to occur for laminates manufactured via resin infusion/transfer methods. However, non-woven microfibre veils may act as flow distribution media because of their highly permeable nature and could create a non-uniform flow front during infusion, leading to porosity in the interleaved regions [105]. A post-infusion dwelling step before the final cure can be carried out to reduce the porosity levels caused by such non-uniform flow phenomenon [86].

Alternatively, non-woven veils composed of predominantly continuous nanofibres manufactured with electro-spinning technology have received attention over the last decades [36, 107-112]. Electrospun nanofibre veils have an ultra-high aspect ratio and specific surface area (much higher than that of microfibre veils) due to their nanofibres (i.e. with a diameter less than a micron). Nanofibres, which can be manufactured with a wide range of thermoplastic polymer and other material alternatives, have higher mechanical properties than their bulk phase with aligned molecular orientation along the fibre direction and with a reduced amount of defects/flaws. Electrospun nanofibre veils are highly compatible with composite laminate manufacturing techniques and can significantly reduce the interleave thickness (compared to microfiber veils). Nanofibre veils can be introduced as interlaminar tougheners in two ways: (a) directly spinning/depositing on the base fibre preforms [113-117], and (b) spinning/collecting on a collector as a stand-alone non-woven veil and later interleaving during the laminate stacking [116118]. The direct deposition can be beneficial as nanofibres are in direct contact with reinforcement fibres but may cause interaction between fabric/prepreg and electrospinning solvents/chemicals. In addition, environmental conditions (i.e. temperature, humidity, out-of-freezer time) must be carefully monitored while electrospinning on prepreg materials to maintain the properties of prepreg layers. The transfer 
from the collector to the interlaminar region needs to be handled carefully to prevent surface contamination and veil damage. By interleaving the nanofibre veils, the strength and stiffness of composite laminates can be maintained or even slightly be increased $[85,113,114,116,117,119,120]$ up to a critical veil thickness [84, 121, 122]. Electro-spinning can be used to produce different forms of nanofibre veils such as core-shell nanofibre veils (i.e. with co-axial electro-spinning) and blending of mixed fibres from different materials (i.e. dissolvable and undissolvable fibres) [123, 124]. By selecting the proportion of different materials, novel electrospun nanofibre veils can be produced for a given set of design requirements and the targeted balance between fracture energy levels (i.e. $G_{I I, C} / G_{I, C}$ ratio). It is also possible to achieve electrospun nanofibre veils with a preferential alignment [125]; however, random distribution/entanglement is shown to be more beneficial for enhancing fracture toughness [126]. Besides, the random fibre distribution, which is convenient to manufacture, is favourable as the delamination in practical applications may propagate in different directions, unlike the pre-determined direction of propagation in fracture test specimens. Non-woven veils can also provide an approximately constant interlaminar thickness which may aid to maintain the adhesive thickness between bonded substrates, which can benefit composite patch repairs and bonded joints [97, 127, 128]. Finally, although non-woven veils (both microfibre and electrospun nanofibre veils) are lightweight materials, it is worth noting that the toughener veils may introduce additional weight at the structural scale $[10,11]$.

\subsection{Non-woven veils: toughening mechanisms}

The effectiveness of toughening mechanisms of non-woven veils strongly depends on the interaction of fibres with the surrounding matrix (i.e. fibre-matrix adhesion) and the veil fibres' mechanical behaviour. In the case of undissolvable veils (i.e. in which the veil fibres maintain their fibrous form during and after the manufacturing process), the fibre-matrix debonding, matrix yielding and crack coalescence in the resin essentially occur ahead of the crack front and absorb the fracture energy (as intrinsic mechanisms). As an extrinsic mechanism (i.e. a phenomenon that occurs at the crack wake), fibre bridging contributes to the resistance to crack opening. The fibre bridging mechanism can be recognised in the fracture energy vs crack length curves (i.e. R-curves) as a gradual increase in the fracture energy [10] (i.e. rising R-curve). A plateau might be reached at a certain crack length when the fibre bridging is eventually saturated. However, if a reduction/decline in the fracture energy is observed with the increased crack length (i.e. falling R-curve), it may indicate that less fibre bridging is taking place as the crack grows, in comparison to the early levels of crack growth [91]. This is often caused by crack deflection from the interlaminar region into the intralaminar regions or veil/lamina interface, which is discussed in Section 5.2. Eventually, the bridged veil fibres break and are pulled out or peeled off from the matrix. During crack propagation, the surrounding matrix can experience spalling, snubbing or void growth [129-132]. These toughening mechanisms in non-woven veil interleaved laminates are illustrated in Fig. 2.

Fibre breakage occurs in the case of sufficient bonding and long fibre length. Sufficiently strong bonding prevents the fibres from debonding, being pulled out or peeled off easily, and leads to fibre breakage at the end of the fibre bridging $[118,133]$. In nanofibre veils, the fibres are long and continuous, and almost no free fibre ends exist due to the continuous spinning process. Hence, numerous fibres form bridges between the crack faces and break. During fibre breakage, ductile (tough) fibres can absorb energy by stretching and eventually yielding before breaking. In contrast, brittle fibres exhibit a lower energy absorption capability due to their low failure strain. As a result, broken fibres can exhibit fibrillations or necking depending on the fibre type. For example, interleaves made of Kevlar microfibres show extensive fibrillation upon breakage under mode-I and mode-II fracture [99, 134]. In contrast, ductile fibre fracture with yielding/necking can be seen in thermoplastic nanofibres due to their high strain to failure [118, 135].

Fibre pull-out may occur due to fibre bridging because of weak fibre-matrix bonding and short fibre lengths. The fibres progressively debond from the surrounding matrix, start sliding and are finally pulled out from the surrounding matrix. Fibre-matrix friction can contribute to energy dissipation during sliding (i.e. frictional pull-out). When a fibre is completely pulled out, one end of the fibre is embedded 


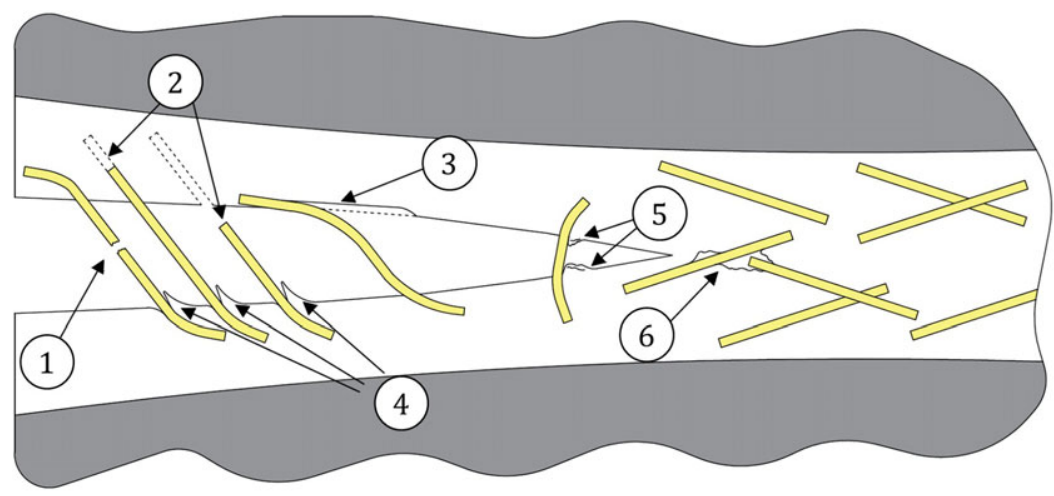
1) Fibre breakage
2) Fibre pull-out
4) Matrix spalling
3) Fibre peel-off
5) Snubbing
6) Fibre-matrix debonding and crack coalescence

Figure 2. An illustration of extrinsic and intrinsic toughening mechanisms in non-woven veil interleaved laminates.

in the matrix, and the other end is free of any physical constraint. As no load can thus be transferred over the fibre length, the fibre no longer contributes to energy dissipation. The pull-out mechanism often occurs in non-woven microfibre veils having chopped/short fibres. Furthermore, the veil fibres are peeled off from the surrounding matrix (i.e. crack growth at the fibre-matrix interface). With matrix cracks in the interleaved region, fibres and matrix may debond and partially expose the fibre surfaces along the fibre axis. Subsequently, the fibres gradually debond/peel-off from the surrounding matrix with a limited contribution to energy dissipation as damage/crack propagates [135]. The fibre-matrix interaction is a governing factor in fibre bridging mechanisms. A weak fibre-matrix adhesion could be favourable for dissipating energy $[14,81,91,104,136,137]$ in the case of microfibre veils to trigger the abovementioned toughening mechanisms. In contrast, an enhanced fibre-matrix bonding may delay the crack accumulation and improves the fracture energy [35, 138]. As a result, fewer fibres debond from the surrounding matrix and participate in fibre bridging, which results in relatively low fracture energy enhancement from crack onset to crack propagation [35, 138, 139]. However, if the adhesion between veil fibres and the resin is excessively strong or the veil/lamina interface is weak, no crack can accumulate and propagate in the interleaved region. Instead, the crack deviates and predominantly propagates into the untoughened laminae as an intralaminar crack, or crack grows at the veil/lamina interface [91, 101, 118] (i.e. crack propagation via energetically favourable path). Thus, the damage/toughening mechanisms cannot be initiated and absorb energy. In such a case, the areal weight is less prominent on the obtained fracture energy enhancements [116]. The surface properties of interleaving fibres can be altered by different approaches (i.e. ultraviolet irradiation [139, 140], hygrothermal conditioning [81, 136], different fibre sizing or particle deposition [138]) to introduce the aforementioned toughening mechanisms. The extrinsic mechanisms (i.e. fibre breakage, pull-out and peel-off) as well as the intrinsic mechanisms, can simultaneously occur during crack growth in veil toughened interfaces due to the randomness associated with the fibre distribution in veils, yet the contribution of each mechanism in enhancing fracture toughness may differ depending on the interactions between the veil fibres and the neighbouring matrix.

The morphology of the veil interleaved region obtained after curing the resin is an important factor. Although the veils are produced in a fibrous form, veil fibres made of materials with lower melting temperatures than the resin cure temperature (i.e. usually, thermoplastic with low melting point such as polycaprolactone with $T_{\text {melt }} \approx 60^{\circ} \mathrm{C}$ ) cannot maintain their initial fibrous network. Fibres can melt during resin cure and dissolve [141], phase-separate [85, 123], phase-invert [142] or create bead-like structures 
in the fibrous network [113]. If the resin or mould is preheated to an elevated temperature for resin infusion/transfer, the dissolvable veil may melt before/during infusion and migrate with the resin flow. This results in an uneven toughener distribution in the interlaminar region and, consequently, lead to varying fracture toughness [142, 143]. The veil fibres may also melt during resin post-cure and re-solidify into their fibrous form upon cooldown (i.e. $T_{\text {cure }}<T_{\text {melt }}<T_{\text {post-cure }}$ ) $[36,116]$. In the case of dissolved fibres, the extrinsic toughening mechanisms such as fibre bridging and the associated toughening mechanisms cannot be introduced. But dissolvable veils can alter matrix ductility and improve energy dissipation via plastic deformations. Moreover, phase-separated or phase-inverted particles contribute to energy dissipation via particle debonding, cavitation, shear yielding, void growth and crack deflection, and thus help to enhance interlaminar fracture toughness [144]. A blend of dissolved and undissolved veil can lead to higher interlaminar fracture toughness because of the toughening mechanisms induced by both morphologies [123, 124, 141], which is discussed Section 6.2.

\subsection{Particle and non-woven veil toughening: limitations}

\subsection{Interlaminar thickness: effect on fracture toughness}

In the case of particle toughening, even though the trade-off between manufacturability and desired properties is somewhat balanced by adjusting the particle type, content and manufacturing process, it is important to note that the enhanced fracture toughness of the particle toughened bulk matrix may not fully be attained in situ (i.e. in composite laminates) to improve intralaminar and interlaminar toughness [19]. This phenomenon of limited fracture toughness translation is mainly attributed to the restriction of the fracture process zone size at the crack front due to the presence of reinforcement fibres $[24,31,63$, 145]. Relatively rigid reinforcement fibres and limited thickness of the interlaminar region suppress the formation of the fracture process zone required and thus alter the damage and toughening mechanisms. Nevertheless, the in situ composite fracture energy may well match with corresponding bulk matrix fracture toughness (i.e. $G_{I, C}^{\text {composite }} \approx G_{I, C}^{\text {matrix }}$ ) up to certain level of fracture toughness [15, 32, 145-147]. Although there are different limits suggested in the literature, it is hard to specify a generalised threshold below which the bulk matrix toughness can be fully translated to in situ fracture toughness. This uncertainty arises as various particle tougheners in different material systems are used, leading to dissimilar toughening effects for each toughened material system. When the interlaminar region is relatively thick and larger than the bulk matrix fracture process zone size, the fibre restriction is relieved and the in situ fracture toughness (i.e. interlaminar fracture toughness) can match the bulk matrix fracture toughness up to 1,000 to $2,000 \mathrm{~J} / \mathrm{m}^{2}[34,148,149]$.

In the case of non-woven veil interleaving, it is observed that the higher the number of fibres involved in the fracture, the higher the interlaminar fracture energy $[92,115]$. This can be achieved by using veils with high areal weights or by reducing the veil fibre diameter for the same areal weight (e.g. using nanofibres instead of microfibres [36]). As highlighted in Section 3, increasing the areal weight of veils results in an increased interleave thickness (i.e. thicker interlaminar region), which is more pronounced in microfibre veils, see Fig. 1(b) and (c). The thicker interleave contains an increased number of fibres and a thicker matrix region (i.e. larger volume of resin). This region may be considered as a resin-rich region as the volume fraction of veil fibres is low, see Fig. 1(c). As the fracture process zone is confined to a thin matrix region between neighbouring laminae in an untoughened (i.e. without interleaving) interlaminar region, increasing the interlaminar thickness up to a critical value results in higher fracture toughness due to the increased size of the unconstrained fracture process zone [150-152]. The fracture energy enhancement that arises from the increased areal weight of non-woven veils may not thus be solely attributed to the increased number of veil fibres, and the increased interlaminar resin thickness could also contribute to the fracture toughness enhancement. In fact, the above discussion applies to all forms of interleaving, including particle and film interleaves, as they increase the interlaminar thickness. However, only a limited amount of work has been done to uncouple and fully understand the individual contributions of the interlaminar matrix region and the toughener phase [149, 153, 154]. 


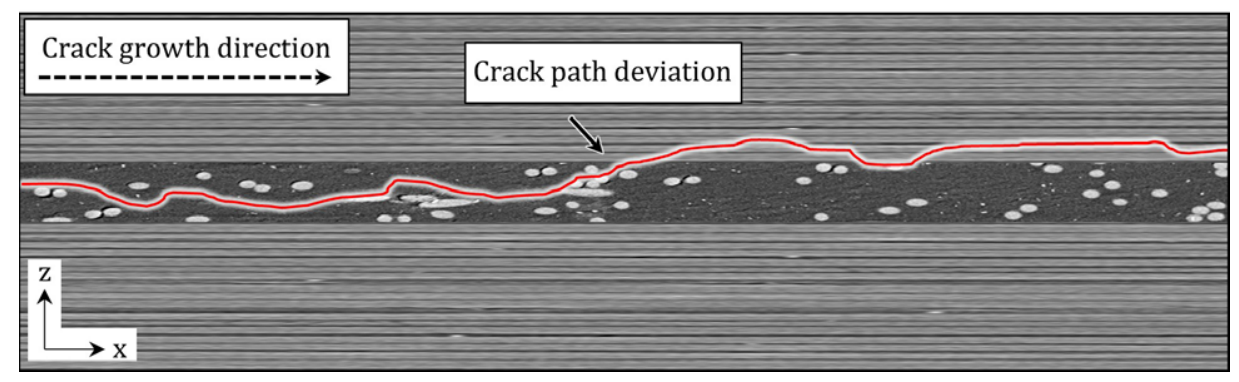

Figure 3. An illustration of crack path deviation from interleaved region to energetically favourable path, i.e. interleave/lamina interface or intralaminar region (the $x$ and $z$ axes represent fibre direction and through-the-thickness directions, respectively).

\subsection{Crack path deviation: energetically favourable paths}

With toughened interlaminar regions via various types of interleaving materials (i.e. non-woven veils, films, particles, bucky papers or CNT forests), the crack front may deviate and propagate into the energetically favourable path $[21,42,73,91,101,116,139,155-157]$, see Fig. 3. The type of loading (i.e. quasi-static or cyclic) can also affect the crack length at which the crack deviated $[42,135]$. The energetically favourable path is either the intralaminar regions next to the interleaved region or the interleave/lamina interface when the interleave/lamina bonding is relatively weak. Once the crack is diverted into a lower toughness region, it is improbable that further crack growth occurs in the interleaved region. However, when the crack front encounters some resin-rich regions (i.e. in the wavy surface of woven laminates or stitching induced resin pockets of non-crimp fabric laminates), some contribution to the fracture energy absorption from the interleave can be obtained [91, 118, 158]. Discontinuous interleave patches (i.e. strips) perpendicular to the crack growth direction can be employed to 'lure' the crack back to interleaved regions $[118,159,160]$. Hence, the crack can be arrested in the discontinuous interleaved regions, following a certain length of intralaminar growth. Although this method introduces fluctuations in the R-curves (i.e. varying fracture toughness along the crack path), the average fracture energy of the toughened interlaminar regions can be considerably higher than that of the untoughened interlaminar regions. The width and spacing of the veil strips can be optimised, or specially designed interleave structures [161] can be used to obtain an optimum outcome in terms of interlaminar fracture toughness. Another solution proposed to maintain the crack growth in the interleave is via introducing stress concentrations in the interlaminar region such that the increased local stresses initiate toughening mechanisms further away from the crack tip [162]. Introducing tough interphase between the interleave and the neighbouring laminae could also be effective to maintain interlaminar crack growth [42]. Furthermore, increasing the fracture toughness of intralaminar regions can be considered to control the crack path. In this case, a particle toughened resin can be infused/impregnated to the intralaminar regions. Nanoparticles (i.e. rubber, nano-silica or carbon nanomaterials) can penetrate the neighbouring laminae due to their smaller size than the inter-fibre spacing of the reinforcement fibres. The fracture enhancement of interleaving methods is relatively more reliable for the crack onset [157] due to crack deviation, thus a localised/selective toughening can be applied in the vicinity of the regions of stress concentrations such as holes and free-edges [114]. Likewise, non-woven veils can be introduced to pre-determined machining/drilling sites to suppress the peel-up and push-out delaminations caused by the machining tool [163].

\subsection{Trends and research opportunities}

\subsection{Mode-I and II fracture: effect of particles and non-woven veils}

It has been reviewed in the previous sections that various tougheners can be used for improving the interlaminar and intralaminar fracture toughness of composite laminates. Depending on the toughener type, 


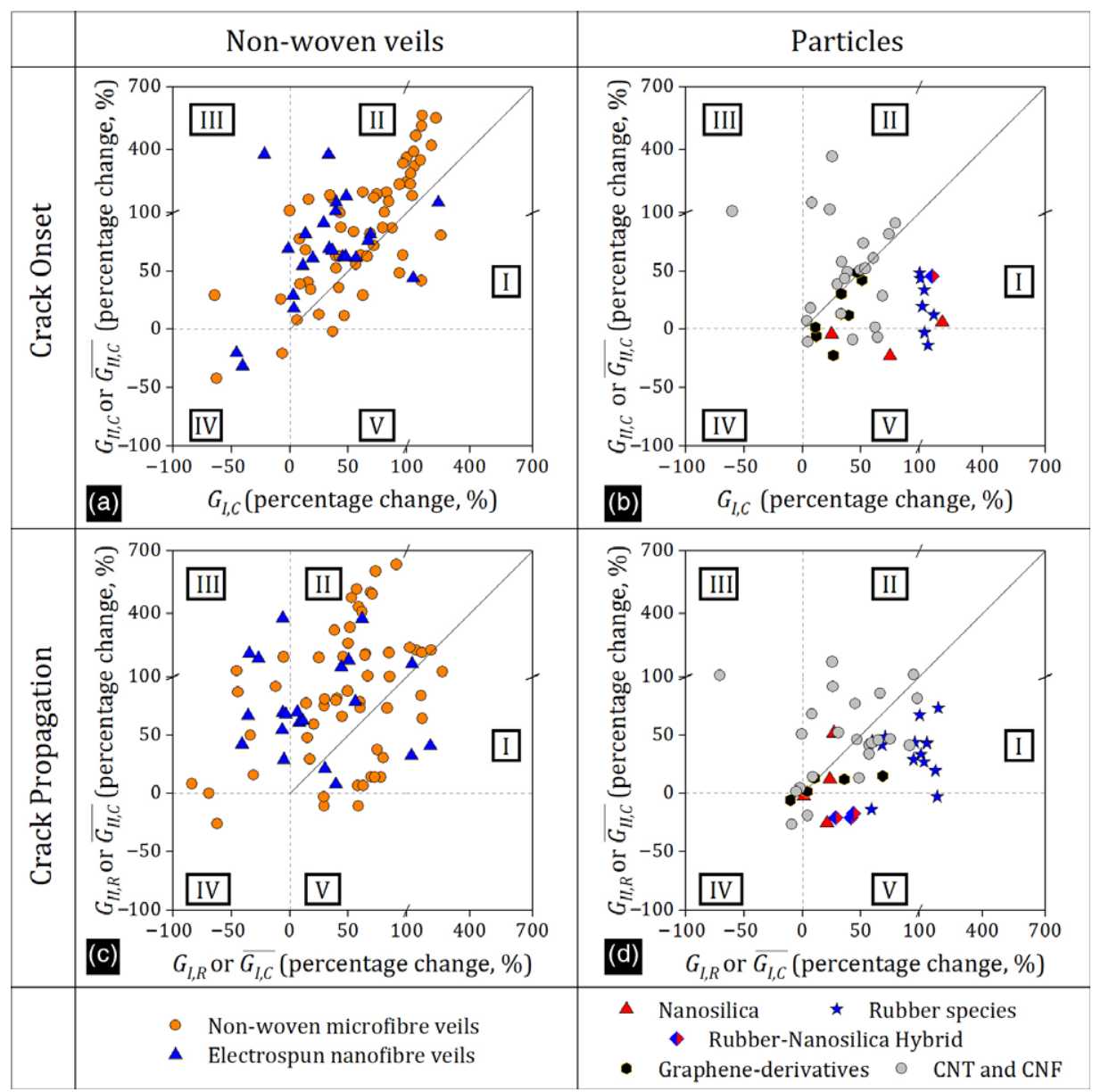

Figure 4. A comparison of percentage changes in crack onset and crack propagation fracture energies in mode-I and mode-II fracture as compared to the respective baseline values for glass or carbon fibre reinforced epoxy composite laminates toughened with non-woven microfibre and electrospun nanofibre veils in (a) and (c) (data extracted from Refs 36, 90, 92, 95, 100, 102, 115, 118, 123, 124, 139, 155, 158, 161, 165-172); and toughened with rubber, nano-silica, CNT, CNF and graphene-derivatives in (b) and (d) (data extracted from Refs 27, 30, 50, 53, 54, 56, 62-64, 69, 70, 78, 173-180). Note that dissolvable non-woven veils and multiscale toughened composites are not included in the plots, and both axes in all the plots are bi-linearly scaled for convenience.

process parameters and conditions explored, a varying level of success has been observed in enhancing the fracture properties. Thus, a straightforward evaluation is presented in Fig. 4 by using the data published in the literature to compare the enhancements achieved in interlaminar fracture toughness with different toughener materials. A comparison of the percentage change in the interlaminar fracture energies of mode-I vs mode-II obtained by non-woven veils and particle tougheners is shown (see Fig. 4). The fracture energies at crack onset (i.e. $G_{I, C}$ and $G_{I I, C}$ ) and during crack propagation (i.e. $G_{I, R}$ and $G_{I I, R}$ ) are evaluated for non-woven veils and particle tougheners separately. The plots in Fig. 4 are divided into five regions as follows: region-I, the toughener is more beneficial to mode-I as compared to mode-II; region-II, the toughener is more beneficial to mode-II as compared to mode-I; region-III, the toughener is beneficial to mode-II but detrimental to mode-I; region-IV, the toughener is detrimental for both mode-I and mode-II; and region-V, the toughener is beneficial for mode-I but detrimental for mode-II. 
Figure 4(a) and (c) compare the percentage changes in fracture energies at the crack onset (i.e. $G_{I, C}$ and $G_{I I, C}$ ) for non-woven veils and particles, respectively. Similarly, Fig. 4(b) and d compare the percentage change in fracture energies during crack propagation (i.e. $G_{I, R}$ and $G_{I I, R}$ ).

Numerous research articles show that various toughening routes can modify interlaminar fracture toughness. In some publications, the data for both mode-I and mode-II fracture energies are not available for the material system explored, while most of the fracture studies are focused on mode-I fracture properties. It is understandable that the mode-I fracture requires less energy compared to mode-II, hence considered to be more critical. Additionally, mode-I fracture energies provide a basis for direct comparison between fracture energies of unreinforced matrix and composite laminates. However, mode-II fracture energy is also an important property as it can play a significant role in the case of in-plane shear dominant loading conditions $[11,164]$. In addition to that, the interpretation of resulting fracture energies varies in the literature. For example, only $G_{I, R}$ and $G_{I I, R}$ are reported in some publications whereas some other publications only publish $G_{I, C}$ and $G_{I I, C}$ before any R-curve behaviour is observed. Thus, some of the data points in the crack onset graphs (Fig. 4(a) and (c)) may not have the corresponding values in crack propagation (Fig. 4(b) and (d)) or vice versa. Besides, a number of publications feature average fracture energies for mode-I and mode-II (i.e. $\overline{G_{I, C}}$ and $\overline{G_{I I, C}}$ ), which is to represent $G_{I, R}$ and $G_{I I, R}$, respectively. In fact, the crack onset and crack propagation are easy to distinguish in mode-I fracture tests due to the predominantly stable crack growth. However, mode-II fracture tests may result in early unstable crack growth and clear identification of $G_{I I, C}$ and $G_{I I, R}$ is not always straightforward. In such cases, when mode-II fracture energy is disclosed in the form of a single value (such as $\overline{G_{I I, C}}$ or $G_{I I, C}$ ), it is assumed that the given value represents both $G_{I I, C}$ and $G_{I I, R}$, for the sake of completeness of Fig. 4. As a result, the number of data used for the current evaluation is limited to some extent, especially for particle tougheners.

It can be seen in Fig. 4(a) that non-woven veils are generally more beneficial for $G_{I I, C}$ compared to $G_{I, C}$. The majority of the data points are in region-II. The same applies to Fig. 4(c), but the data points are more scattered. This observation is consistent with some published literature, where mode-II fracture toughness is enhanced more than mode-I fracture toughness in the case of non-woven veil interleaves [36, 97, 124]. The data points in regions III, IV and V of Fig. 4(c) indicates that the crack propagation energies are lower than the baseline values. It may indicate that both extrinsic and intrinsic toughening mechanisms of non-woven veils have not effectively contributed to the energy dissipation in crack growth, which could be related to the crack path deviation, as discussed in Section 5.2. Similarly, high aspect ratio particles (i.e. CNT, CNF and graphene-derivatives) are not only beneficial for $G_{I, C}$ but also for $G_{I I, C}$ (see Fig. 4(b)). CNT and CNF particles maintain such trend in crack propagation (see Fig. $4(\mathrm{~d})$ ), while graphene-derivatives tend to be relatively more beneficial for $G_{I, R}$. This may be attributed to tubular/fibrous morphology of CNT and CNF particles similar to non-woven veils, which can bridge the crack faces $[77,78]$. Near-spherical particle tougheners of rubber, nano-silica and their hybrids are mainly beneficial for $G_{I, C}$ (see Fig. 4(b)). During crack propagation, the contribution of nano-silica is comparatively limited while rubber particles maintain their trend being relatively more beneficial to mode-I fracture (see Fig. 4(d)). Thermoplastic particles are not included in Fig. 4 as the particle formation depends on several aspects, as discussed in Section 2. Nonetheless, it should be noted that the majority of the data in Fig. 4(a) and (c) are obtained from undissolvable thermoplastic non-woven veils.

\subsection{Multi-scale toughening and multi-functionality}

The multiscale toughening methods refer to the processing routes that utilise two or more tougheners, which could be of different scales and different morphologies, to improve the fracture properties of composite laminates. In comparison, multifunctionality in composites offers superior material properties for engineering design requirements typically including, but not limited to, electrical, mechanical and thermal properties. Additional particle phases can be incorporated together with non-woven veils to induce multifunctionality while enhancing fracture resistance and tolerance. It can be achieved by ensuring the co-existence of the non-woven veil and the additional phase in the interlaminar region. 
Non-woven veils can be used as a carrier of additional phases such as carbon nanotubes (CNT) [71, 72, 144, 172], graphene nanoplatelets (GNP) [71], carbon black [138] and silver nanowires [170]. The additional phase can be deposited onto the veil fibres by vacuum filtering [144], hand brushing [138], spray coating [71, 72] or immersion coating [170]. The deposited additional phase directly affects the veil fibre/matrix adhesion and accordingly results in a change in the fracture properties. It may lead to an increase or decrease in fracture toughness, which depends on many aspects such as the veil fibre, additional phase-resin compatibility, distribution of the additional phase and final morphology of the veil. In particular, the distribution of the additional phase is vital as an uneven distribution could lead to varying interlaminar fracture toughness. This approach is likely to minimise the particle content used to achieve enhanced fracture properties, similar to coating reinforcement fibres with particle tougheners [35]. This approach can also be explored to easily transfer multi-functional particles that tend to agglomerate when mixed into the resin (e.g. carbon-based nano-fillers), as discussed in Section 2.

Another way to achieve multiscale toughening using non-woven veils is via blending the nano-scale particles into the electrospinning solution, then electrospinning nanofibre veils [113, 125, 166, 181]. In this approach, the additional phase is not deposited on the surface of the veil but embedded in the veil fibres and a particle-modified fibre is obtained. Depending on the type and amount of the additional phase, the mechanical properties (i.e. stiffness and strength) and the morphology of electrospun nanofibre can be altered. This can lead to enhanced energy absorption during fibre bridging and results in enhanced fracture toughness, in comparison to the neat veils $[166,181]$. When electrospun nanofibres are produced using a thermoplastic with a low melting point, the additional phase is dispersed at the interlaminar region as nanofibres melt and phase separate [125].

Another approach to obtain a multiscale toughened composite laminate with non-woven veils is either by using a particle blended resin as the matrix phase or by obtaining additional particulate phase at the interlaminar region as a result of phase separation after dissolving [123, 124, 141, 165]. This approach causes no direct changes in either the fibre properties or the fibre-matrix interface of the veil fibres. Instead, the additional phase toughens the matrix that surrounds the non-woven veil. When a particle blended matrix is infused into non-woven veil interleaved fibre preforms, intralaminar regions (i.e. within lamina) are toughened with particles, while interlaminar regions are multiscale toughened with the nonwoven veil and the particles. Moreover, as highlighted in Section 5.1, the thickness of interlaminar region can affect the fracture process zone at the crack tip and influence the fracture toughness enhancement. Therefore, this multi-scale toughening approach can lead to a larger fracture process zone due to the increased interlaminar thickness, which can aid to obtain a higher contribution to the fracture toughness from the particle blended matrix.

A list of some multi-scale toughened composites is given in Table 1 with non-woven veil toughening and multiscale toughening. It can be seen that multiscale toughening offers higher fracture toughness enhancements when compared to non-woven veil interleaving. These enhancements can be additive or even synergistic. However, additional tougheners cannot contribute to fracture toughness or even become detrimental above a specific limit $[71,125]$. Nevertheless, by adjusting the proportions of both toughener phases, multiscale toughened systems could be tailored to obtain desired fracture toughness enhancement in mode-I and mode-II.

In addition to the fracture toughness enhancement, multifunctionality is desirable in composite laminates to combine various material properties. For example, non-woven veils can be selected such that, following damage events, the veil fibres melt upon the application of heat and bond the fracture surfaces together. Therefore, the fracture toughness and other mechanical properties can be recovered [182, 183]. Vibration damping is another important capability of thermoplastic-based interleaving due to their viscoelastic behaviour [184], which applies to thermoplastic non-woven veils [81, 93, 185]. However, thermoplastic non-woven veils significantly reduce the electrical conductivity of composite laminates. Electrical conductivity is of importance to improve an aircraft's ability to withstand lightning strikes. The conventional way to provide lightning strike protection is using a mesh of conductive material (i.e. metallic mesh), which adds to the overall weight. Hence, improving the electrical conductivity (i.e. decreasing the electrical resistivity) with various conductive particles carried by non-woven veils could 
Table 1. A comparison of fracture energy enhancement via multiscale toughening in composite laminates with non-woven veils and particles

\begin{tabular}{|c|c|c|c|c|}
\hline Ref. & $\begin{array}{l}\text { Non-woven } \\
\text { veil }\end{array}$ & $\begin{array}{l}\text { Change in fracture } \\
\text { energy compared } \\
\text { to baseline }\end{array}$ & $\begin{array}{l}\text { Multi-scale } \\
\text { toughening route }\end{array}$ & $\begin{array}{l}\text { Change in fracture } \\
\text { energy compared } \\
\text { to baseline }\end{array}$ \\
\hline Lee et al. [172] & $\begin{array}{l}\text { Carbon fibre } \\
\text { microfibre veil } \\
(10 \mathrm{gsm})\end{array}$ & $\begin{array}{l}\% \overline{G_{I, C}}=-5 \% \\
\% \overline{G_{I I, C}}=+194 \%\end{array}$ & $\begin{array}{l}\text { CNT }(15 \% \mathrm{wt}) \text { on } \\
\text { the veil }\end{array}$ & $\begin{array}{l}\% \overline{G_{I, C}}=+35 \% \\
\% \overline{G_{I I, C}}=+246 \%\end{array}$ \\
\hline Zheng et al. [144] & $\begin{array}{l}\text { Dissolvable PSF } \\
\text { nanofibre veil } \\
\text { CNT }(10 \% \text { wt) on the } \\
\text { veil }\end{array}$ & $\begin{array}{l}\% \overline{G_{I, C}}=+23 \% \\
\% \overline{G_{I I, C}}=+17 \% \\
\% \overline{G_{I, C}}=+53 \% \\
\% \overline{G_{I I, C}}=+34 \%\end{array}$ & $\begin{array}{l}\text { CNT }(5 \% w t) \text { on } \\
\text { the veil }\end{array}$ & $\begin{array}{l}\% \overline{G_{I, C}}=+41 \% \\
\% \overline{G_{I I, C}}=+23 \%\end{array}$ \\
\hline Quan et al. [71] & $\begin{array}{l}\text { PPS }^{\mathrm{b}} \text { microfibre veil } \\
(5 \mathrm{gsm})\end{array}$ & $\begin{array}{l}\% G_{I, C} / \% G_{I, R}=+16 \% /+54 \% \\
\% G_{I I, C} / \% G_{I I, R}=+174 \% /+197 \%\end{array}$ & $\begin{array}{l}\text { CNT }(5 \% \mathrm{wt}) \text { on } \\
\text { the veil } \\
\text { CNT }(12 \% \mathrm{wt}) \text { on } \\
\text { the veil } \\
\text { CNT }(22 \% \mathrm{wt}) \text { on } \\
\text { the veil } \\
\text { CNT ( } 29 \% \mathrm{wt}) \text { on } \\
\text { the veil } \\
\text { GNP }(5 \% \mathrm{wt}) \text { on } \\
\text { the veil } \\
\text { GNP }(10 \% \mathrm{wt}) \text { on } \\
\text { the veil } \\
\text { GNP }(20 \% \mathrm{wt}) \text { on } \\
\text { the veil } \\
\text { GNP }(33 \% \mathrm{wt}) \text { on } \\
\text { the veil }\end{array}$ & $\begin{array}{l}\% G_{I, C} / \% G_{I, R}=+36 \% /+71 \% \\
\% G_{I I, C} / \% G_{I I, R}=+200 \% /+211 \% \\
\% G_{I, C} / \% G_{I, R}=+33 \% /+75 \% \\
\% G_{I I, C} / \% G_{I I, R}=+135 \% / 139 \% \\
\% G_{I, C} / \% G_{I, R}=-20 \% /+6 \% \\
\% G_{I I, C} / \% G_{I I, R}=+74 \% /+21 \% \\
\% G_{I, C} / \% G_{I, R}=-30 \% /-14 \% \\
\% G_{I I, C} / \% G_{I I, R}=+101 \% /+103 \\
\% G_{I, C} / \% G_{I, R}=-3 \% /+45 \% \\
\% G_{I I, C} 1 \% G_{I I, R}=+145 \% /+160 \% \\
\% G_{I, C} / \% G_{I, R}=-11 \% /+33 \% \\
\% G_{I I, C} / \% G_{I I, R}=+89 \% /+121 \% \\
\% G_{I, C} 1 \% G_{I, R}=-14 \% /+21 \% \\
\% G_{I I, C} 1 \% G_{I I, R}=+78 \% /+110 \% \\
\% G_{I, C} 1 \% G_{I, R}=-13 \% /+27 \% \\
\% G_{I I, C} / \% G_{I I, R}=+67 \% /+84 \%\end{array}$ \\
\hline
\end{tabular}


Table 1. Continued.

\begin{tabular}{|c|c|c|c|c|}
\hline Ref. & $\begin{array}{l}\text { Non-woven } \\
\text { veil }\end{array}$ & $\begin{array}{l}\text { Change in fracture } \\
\text { energy compared } \\
\text { to baseline }\end{array}$ & $\begin{array}{l}\text { Multi-scale } \\
\text { toughening route }\end{array}$ & $\begin{array}{l}\text { Change in fracture } \\
\text { energy compared } \\
\text { to baseline }\end{array}$ \\
\hline Hamer et al. [166] & $\begin{array}{l}\text { PA66 }{ }^{\mathrm{c}} \text { electrospun } \\
\text { nanofibre veil } \\
(10-12 \mathrm{gsm})\end{array}$ & $\begin{array}{l}\% G_{I, R}=+214 \% \\
\% \overline{G_{I I, C}}=+41 \%\end{array}$ & $\begin{array}{l}\text { CNT (5\%wt) in the } \\
\text { nanofibre }\end{array}$ & $\begin{array}{l}\% G_{I, R}=+290 \% \\
\% G_{I I, C}=+66 \%\end{array}$ \\
\hline Bilge et al. [113] & $\begin{array}{l}\mathrm{P}(\mathrm{St}-\mathrm{co}-\mathrm{GMA})^{\mathrm{d}} \\
\text { electrospun nanofibre } \\
\text { veil }\end{array}$ & $\% \overline{G_{I I, C}}=+55 \%$ & $\begin{array}{l}\text { CNT ( } 1 \% \text { wt) in the } \\
\text { nanofibre }\end{array}$ & $\% \overline{G_{I I, C}}=+68 \%$ \\
\hline $\begin{array}{l}\text { Eskizeybek et al. } \\
\text { [181] }\end{array}$ & & & $\begin{array}{l}\text { CNT ( } 5 \% \text { wt) in the } \\
\text { nanofibre }\end{array}$ & $\% G_{I, C} / \% G_{I, R}=+27 \% /+46 \%$ \\
\hline \multirow[t]{2}{*}{ Li et al. [125] } & $\begin{array}{l}\text { Dissolvable PSF } \\
\text { electrospun nanofibre } \\
\text { veil }\end{array}$ & $\% \overline{G_{I I, C}}=+10 \%$ & $\begin{array}{l}\text { CNT ( } 5 \% \text { wt) in the } \\
\text { nanofibre }\end{array}$ & $\% \overline{G_{I I, C}}=+27 \%$ \\
\hline & & & $\begin{array}{l}\text { CNT (20\%wt) in } \\
\text { the nanofibre }\end{array}$ & $\% \overline{G_{I I, C}}=+38 \%$ \\
\hline
\end{tabular}


Table 1. Continued.

\begin{tabular}{|c|c|c|c|c|}
\hline Quan et al. [141] & $\begin{array}{l}\text { PPS microfibre } \\
\text { veil }(5 \mathrm{gsm})\end{array}$ & $\begin{array}{l}\% G_{I, C} 1 \% G_{I, R}=+16 \% /+65 \% \\
\% G_{I I, C} / \% G_{I I, R}=+163 \% /+209 \% \\
\text { (Prepreg material system) } \\
\% G_{I, C} 1 \% G_{I,}=+6 \% /+29 \% \\
\% G_{I I, C} / \% G_{I I, R}=+8 \% /-11 \% \\
\text { (NCF/epoxy material system) }\end{array}$ & $\begin{array}{l}\text { Meltable PA microfibre veil } \\
(10 \mathrm{gsm})\end{array}$ & $\begin{array}{l}\% G_{I, C} / \% G_{I, R}=+105 \% /+110 \% \\
\% G_{I I, C} / \% G_{I I, R}=+126 \% /+127 \% \\
\% G_{I, C} / \% G_{I, R}=+272 \% /+195 \% \\
\% G_{I I, C} / \% G_{I I, R}=+185 \% /+63 \%\end{array}$ \\
\hline & $\begin{array}{l}\text { PPS microfibre } \\
\text { veil }(10 \mathrm{gsm})\end{array}$ & $\begin{array}{l}\% G_{I, C} 1 \% G_{I, R}=+34 \% /+115 \% \\
\% G_{I I, C} / \% G_{I I, R}=+183 \% /+239 \% \\
(\text { Prepreg material system) } \\
\% G_{I, C} / \% G_{I, R}=+42 \% /+58 \% \\
\% G_{I I, C} / \% G_{I, R}=+36 \% /+7 \% \\
\text { (NCF/epoxy material system) }\end{array}$ & & $\begin{array}{l}\% G_{I, C} / \% G_{I, R}=+128 \% /+170 \% \\
\% G_{I I, C} 1 \% G_{I I, R}=+130 \% /+132 \% \\
\% G_{I, C} / \% G_{I, R}=+262 \% /+193 \% \\
\% G_{I I, C} 1 \% G_{I I, R}=+206 \% /+72 \%\end{array}$ \\
\hline Saghafi et al. [123] & $\begin{array}{l}\text { PA66 electrospun } \\
\text { nanofibre veil }\end{array}$ & $\begin{array}{l}\% \frac{G_{I, C}}{1} \% G_{I, R}=+35 \% /-3 \% \\
\% G_{I I, C}=+68 \%\end{array}$ & $\begin{array}{l}\text { Mix of undissolvable PA66 } \\
\text { and dissolvable PCL } \\
\text { electrospun nanofibre veil }\end{array}$ & $\begin{array}{l}\% G_{I, C} / \% G_{I, R}=+39 \% /+10 \% \\
\% G_{I I, C}=+56 \%\end{array}$ \\
\hline Daelemans et al. [124] & $\begin{array}{l}\text { PA6 electrospun } \\
\text { nanofibre veil } \\
(10 \mathrm{gsm})\end{array}$ & $\begin{array}{l}\% \overline{G_{I, C}}=+6 \% \\
\% \overline{G_{I I, C}}=+70 \%\end{array}$ & $\begin{array}{l}\text { Undissolvable core- } \\
\text { dissolvable shell electrospun } \\
\text { nanofibre veil PA66/PCL } \\
(50 \% \mathrm{wt} / 50 \% \mathrm{wt})(10 \mathrm{gsm}) \\
\text { Undissolvable core- } \\
\text { dissolvable shell electrospun } \\
\text { nanofibre veil PA66/PCL } \\
(70 \% \mathrm{wt} / 30 \% \mathrm{wt})(10 \mathrm{gsm})\end{array}$ & $\begin{array}{l}\% \overline{G_{I, C}}=+42 \% \\
\% \overline{G_{I I, C}}=+53 \% \\
\% \overline{G_{I, C}}=+58 \% \\
\% \overline{G_{I I, C}}=+59 \%\end{array}$ \\
\hline
\end{tabular}


Table 1. Continued.

\begin{tabular}{|c|c|c|c|c|}
\hline Ref. & $\begin{array}{l}\text { Non-woven } \\
\text { veil }\end{array}$ & $\begin{array}{l}\text { Change in fracture } \\
\text { energy compared } \\
\text { to baseline }\end{array}$ & $\begin{array}{l}\text { Multi-scale } \\
\text { toughening route }\end{array}$ & $\begin{array}{l}\text { Change in fracture } \\
\text { energy compared } \\
\text { to baseline }\end{array}$ \\
\hline & & & $\begin{array}{l}\text { Undissolvable core- } \\
\text { dissolvable shell } \\
\text { electrospun nanofibre } \\
\text { veil PA66/PCL } \\
(90 \% \mathrm{wt} / 10 \% \mathrm{wt}) \\
(10 \mathrm{gsm})\end{array}$ & $\begin{array}{l}\% \overline{G_{I, C}}=+18 \% \\
\% \overline{G_{I I, C}}=+43 \%\end{array}$ \\
\hline Zheng et al. [165] & $\begin{array}{l}\text { PA66 electrospun } \\
\text { nanofibre veil }(25 \mathrm{gsm})\end{array}$ & $\begin{array}{l}\% \overline{G_{I, C}}=+30 \% \\
\% \overline{G_{I I, C}}=+21 \%\end{array}$ & $\begin{array}{l}\text { PA66 electrospun } \\
\text { nanofibre veil }(5 \mathrm{gsm}) \text { in } \\
\text { dissolvable PCL film } \\
(20 \mathrm{gsm})\end{array}$ & $\begin{array}{l}\% \overline{G_{I, C}}=+110 \% \\
\% \overline{G_{I I, C}}=+101 \%\end{array}$ \\
\hline
\end{tabular}

a Polysulfone

${ }^{b}$ Polyphenylene sulfide

'Polyamide

${ }^{d}$ Polystyrene-co-glycidyl methacrylate

${ }^{\text {e}}$ Polyacrylonitrile 
lead to significant weight savings while improving the fracture toughness [72, 170, 171, 186, 187]. Furthermore, enhanced electrical conductivity could be explored for structural health monitoring [186]. Even though the additional phases may not be particularly beneficial for the fracture properties, the resulting fracture toughness can still be higher than that of the untoughened composite laminate. A list of some of the published literature on multiscale toughened multifunctional composite laminates with enhanced electrical properties in addition to enhanced fracture energy is given in Table 2.

\subsection{Mechanical properties: effect of particles and non-woven veils}

In the previous sections, the focus was mainly on the quasi-static fracture conditions. But various service conditions such as fatigue, low-velocity impact, post-impact in-plane loading, high strain loading and environmental ageing conditions must be considered to understand the role of third-phase toughening materials on the mechanical behaviour under such loading conditions. With various tougheners, the accumulation and propagation of matrix cracks can be suppressed-leading to lower crack density and delaying final failure (e.g. increasing fatigue life) [188-192]. Interlaminar fatigue crack growth rates can be significantly reduced as tougheners enhance interlaminar fracture energy and suppress the growth of delamination [42, 135, 193, 194]. Similarly, high-strain response can be improved by using third-phase tougheners [195]. The enhanced laminate fracture properties because of the addition of tougheners are also beneficial to improve the damage resistance and tolerance of laminates to low-velocity impact loading. By reducing the extent of impact-induced delamination and damage (i.e. size, depth and area) near the impacted region, the residual compressive strength of laminates can be improved [75, 103, 104, $115,185,196,197]$. However, the selection of tougheners for composite laminates should consider the fracture properties and also take into account in-service environmental conditions. Evaluating the effectiveness of the toughener phases under hygro-thermal conditions, such as cryogenic or elevated temperatures [15, 198, 199], hot-wet conditions [81, 136, 137, 200], thermal ageing [201], is of importance to explore the merits of third-phase tougheners in engineering applications. For example, the properties of tougheners and matrix change with temperature, directly affecting toughening mechanisms $[198,199]$. Similarly, moisture absorption can affect fracture toughness and post-impact properties when laminates are exposed to hot-wet conditions [81, 136, 137, 161, 200].

In addition to experimental studies, understanding the structure-property relationships via analytical and computational modelling is essential. Identifying intralaminar and interlaminar toughening mechanisms, and their contribution, at multiple length scales is necessary to fully understand the sequence and interaction of various mechanisms and toughener types. Models that can accommodate multiple material length scales can play a significant role to determine the contribution of individual toughening mechanisms to the fracture toughness of laminates at macroscale [34, 131, 132, 191, 202]. Moreover, statistical and probabilistic models are necessary to understand the influence of material variability on fracture properties $[92,203]$. By identifying the critical factors contributing to the enhancement of fracture properties, composite laminates with various tougheners could be tailored to specific design requirements.

\subsection{Concluding remarks}

This article reviewed the interlaminar fracture toughness of composite laminates with particle fillers and non-woven fibre veils. The benefits and limitations of both toughening approaches are discussed. The fracture toughness enhancements due to various tougheners are evaluated, and recent research on multiscale toughened multifunctional composite laminates is also compared. The following key points are drawn:

- Although resin infusion/impregnation methods can effectively be used to introduce particle tougheners (e.g. nano-scale particles) into interlaminar and intralaminar regions, an optimum particle content should be determined not only to obtain enhanced fracture toughness but also to prevent 
Table 2. A comparison of enhanced electrical properties and fracture toughness in multiscale toughened multifunctional composite laminates with non-woven veils and particles

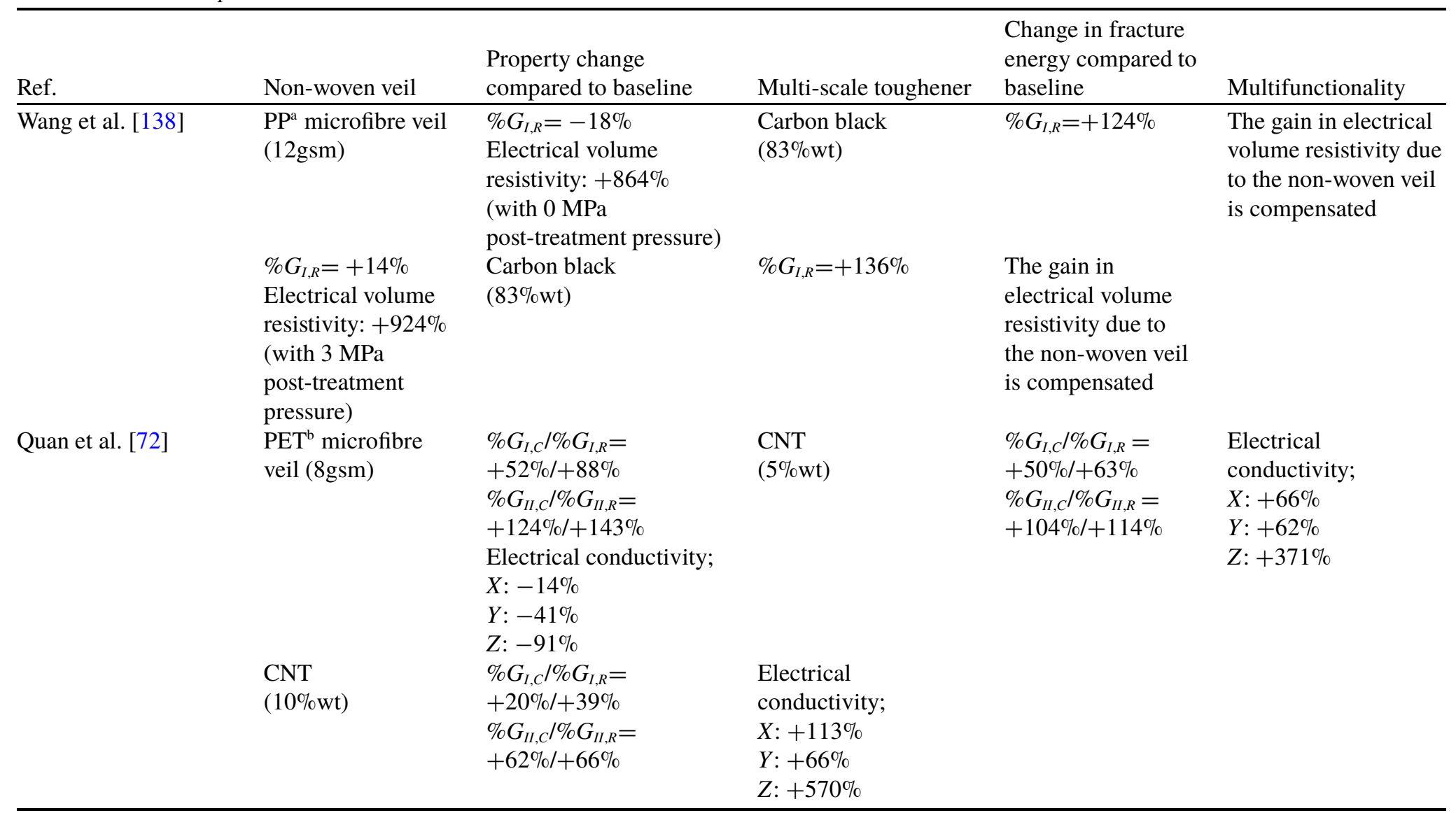


Table 2. Continued.

\begin{tabular}{|c|c|c|c|c|c|}
\hline Ref. & Non-woven veil & $\begin{array}{l}\text { Property change } \\
\text { compared to baseline }\end{array}$ & Multi-scale toughener & $\begin{array}{l}\text { Change in fracture } \\
\text { energy compared to } \\
\text { baseline }\end{array}$ & Multifunctionality \\
\hline Guo et al. [170] & $\begin{array}{l}\text { Nylon microfibre } \\
\text { veil }(16 \mathrm{gsm})\end{array}$ & $\begin{array}{l}\% G_{I, C}=+118 \% \\
\% G_{I I, C}=+236 \% \\
\text { Electrical resistivity; } \\
X:+0 \% \\
Y:-76 \% \\
Z:>+1.2210^{7}\end{array}$ & $\begin{array}{l}\text { Silver nanowire } \\
(9 \% \mathrm{wt})\end{array}$ & $\begin{array}{l}\% G_{I, C}=+118 \% \\
\% G_{I I, C}=+226 \%\end{array}$ & $\begin{array}{l}\text { Electrical resistivity } \\
X:+0 \% \\
Y:-99 \% \\
Z:-91 \%\end{array}$ \\
\hline Guo et al. [171] & $\begin{array}{l}\text { Kevlar microfibre } \\
\text { veil }(\sim 16 \mathrm{gsm})\end{array}$ & $\begin{array}{l}\% G_{I, C}=+72 \% \\
\% G_{I I, C}=+171 \%\end{array}$ & $\begin{array}{l}\text { Silver nanoplatelet } \\
(\sim 72 \% \text { wt })\end{array}$ & $\begin{array}{l}\% G_{I, C}=+37 \% \\
\% G_{I I, C}=+130 \%\end{array}$ & $\begin{array}{l}\text { Electrical resistivity } \\
X:-50 \% \\
Y:-99 \% \\
Z:-96 \%\end{array}$ \\
\hline
\end{tabular}

\section{aPolypropylene}

'Polyethylene terephthalate

The $X, Y$ and $Z$ represent the fibre, transverse and through-the-thickness directions in a unidirectional composite laminate, respectively 
particle agglomeration and maintain the resin properties (e.g. viscosity and glass transition temperature) for processability. For example, low aspect ratio particles such as nano-silica and rubber are particularly promising for low-cost processing methods. In contrast, high aspect ratio particles (e.g. CNTs, CNFs and graphene derivatives) offer significant improvements in fracture toughness, see Fig. 4, but can considerably alter the resin viscosity and lead to particle agglomeration.

- Processing techniques such as coating, spraying or growing/grafting the particles on fibre preforms/prepregs can minimise the particle loading to enhance interlaminar fracture toughness. But the non-uniform distribution of the particles and the compressibility and consolidation of the fibre preforms after such coating/grafting could be an issue.

- Dissolvable thermoplastics tougheners (e.g. particles, films or non-woven veils) are highly processdependent. The variability in the curing process can lead to a dissimilar toughening effect as it directly affects the morphology of the thermoplastic phase and toughener-matrix interaction. Therefore, manufacturing conditions with dissolvable thermoplastic tougheners require careful monitoring and optimisation to obtain the desired toughening efficiency.

- Non-woven veils offer a straightforward toughening approach and do not alter the resin properties (e.g. viscosity and glass transition temperature) for processability. Non-woven microfibre veils are typically inexpensive and mass-producible and offer cost-effective toughening routes. In contrast, nanofibre veils require electrospinning but provide a high specific surface area with a wide range of material combinations.

- Non-woven veils and veils with deposited particles can enhance the fracture toughness of composite laminates but at the expense of increased laminate thickness (i.e. thicker interlaminar region) and reduced overall fibre volume fraction-adversely affecting in-plane laminate properties. The role of interlaminar resin thickness on interlaminar fracture toughness, crack path deviation and toughening mechanisms is not fully understood. As discussed in Section 5.2, the toughening effect occurs as long as the crack propagates within the interleaved region and maintaining an interlaminar crack growth could improve the efficiency of interleaving techniques.

- High aspect ratio tougheners with fibrous/tubular geometry (i.e. non-woven veils, carbon nanotubes and carbon nanofibres) can significantly enhance mode-II fracture toughness in addition to mode-I fracture toughness. In contrast, low aspect ratio nanoparticles (i.e. nano-silica and rubber particles) are more effective in mode-I fracture (see Fig. 4).

- Various multi-scale toughening routes can be explored to enhance further the interlaminar fracture energy of laminates by combining particle tougheners and non-woven veils (see Table 1). Furthermore, multifunctionality aspects with non-woven veil and particle tougheners can offer additional benefits such as enhanced electrical conductivity, thermal healing and vibration damping.

- Non-woven veils and particle tougheners can also affect the damage resistance and tolerance of laminates in various in-service conditions such as fatigue, low-velocity impact and hot-wet conditions; however, as the published literature is limited, further studies are necessary to fully understand such effects. In addition, advanced computational models are essential to identifying intralaminar and interlaminar toughening mechanisms and their contribution, and to fully understand the sequence and interaction at multiple length scales of various mechanisms and the role of toughener types.

Acknowledgements. The authors gratefully acknowledge The Ministry of National Education (MEB) of the Republic of Turkey for the doctoral scholarship granted for Oğuzcan İnal.

\section{References}

[1] Richardson, M. and Wisheart, M. Review of low-velocity impact properties of composite materials, Compos. Part A Appl. Sci. Manuf., 1996, 27, (12), pp 1123-1131.

[2] Soutis, C. and Curtis, P. Prediction of the post-impact compressive strength of CFRP laminated composites. Composites Science and Technology, 1996. 56(6), pp 677-684. 
[3] İnal, O., Balğkoğlu, F. and Ataş, A. Bolted joints in quasi-unidirectional glass-fibre NCF composite laminates, Compos. Struct., 2018. 183, pp 536-544.

[4] Cantwell, W.J. and Morton, J. The impact resistance of composite materials - a review, Composites, 1991, 22, (5), pp 347-362.

[5] Katnam, K.B., Da Silva, L. and Young, T. Bonded repair of composite aircraft structures: a review of scientific challenges and opportunities, Progress Aerospace Sci., 2013, 61, pp 26-42.

[6] Ritchie, R.O. The conflicts between strength and toughness. Nature Mater., 2011, 10, (11), pp 817-822.

[7] Mouritz, A. and Cox, B. A mechanistic interpretation of the comparative in-plane mechanical properties of 3D woven, stitched and pinned composites, Compos. Part A Appl. Sci. Manuf., 2010, 41, (6), pp 709-728.

[8] Dransfield, K.A., Jain, L.K. and Mai, Y.-W. On the effects of stitching in CFRPs-I. Mode I delamination toughness, Compos. Sci. Technol., 1998, 58, (6), pp 815-827.

[9] Jain, L.K., Dransfield, K.A. and Mai, Y.-W. On the effects of stitching in CFRPs-II. Mode II delamination toughness, Compos. Sci. Technol., 1998, 58, (6), pp 829-837.

[10] Sela, N. and Ishai, O. Interlaminar fracture toughness and toughening of laminated composite materials: a review, Composites, 1989, 20, (5), pp 423-435.

[11] Greenhalgh, E. and Hiley, M. The assessment of novel materials and processes for the impact tolerant design of stiffened composite aerospace structures, Compos. Part A Appl. Sci. Manuf., 2003, 34, (2), pp 151-161.

[12] Nash, N., Young, T., McGrail, P. and Stanley, W. Inclusion of a thermoplastic phase to improve impact and post-impact performances of carbon fibre reinforced thermosetting composites-a review, Mater. Des., 2015, 85, pp 582-597.

[13] Tang, Y., Ye, L., Zhang, Z. and Friedrich, K. Interlaminar fracture toughness and CAI strength of fibre-reinforced composites with nanoparticles-a review, Compos. Sci. Technol., 2013, 86, pp 26-37.

[14] Soutis, C. Fibre reinforced composites in aircraft construction, Prog. Aerospace Sci., 2005, 41, (2), pp 143-151.

[15] Carolan, D., Ivankovic, A., Kinloch, A., Sprenger, S. and Taylor, A. Toughened carbon fibre-reinforced polymer composites with nanoparticle-modified epoxy matrices, J. Mater. Sci., 2017, 52, (3), pp 1767-1788.

[16] Kinloch, A., Mohammed, R., Taylor, A., Sprenger, S. and Egan, D. The interlaminar toughness of carbon-fibre reinforced plastic composites using 'hybrid-toughened'matrices, J. Mater. Sci., 2006, 41, (15), pp 5043-5046.

[17] Jumahat, A., Soutis, C., Jones, F. and Hodzic, A. Compressive behaviour of nanoclay modified aerospace grade epoxy polymer, Plast. Rubber Compos., 2012, 41, (6), pp 225-232.

[18] Hodgkin, J., Simon, G.P. and Varley, R.J. Thermoplastic toughening of epoxy resins: a critical review, Polym. Adv. Technol., 1998, 9, (1), pp 3-10.

[19] Liu, K. and Macosko, C.W. Can nanoparticle toughen fiber-reinforced thermosetting polymers? J. Mater. Sci., 2019, 54, (6), pp 4471-4483.

[20] Hussain, F., Hojjati, M., Okamoto, M. and Gorga, R.E. Polymer-matrix nanocomposites, processing, manufacturing, and application: an overview, J. Compos. Mater., 2006, 40, (17), pp 1511-1575.

[21] Wang, W., Takao, Y., Matsubara, T. and Kim, H. Improvement of the interlaminar fracture toughness of composite laminates by whisker reinforced interlamination, Compos. Sci. Technol., 2002, 62, (6), pp 767-774.

[22] Wichmann, M.H., Sumfleth, J., Gojny, F.H., Quaresimin, M., Fiedler, B. and Schulte, K. Glass-fibre-reinforced composites with enhanced mechanical and electrical properties-benefits and limitations of a nanoparticle modified matrix, Eng. Fract. Mech., 2006, 73, (16), pp 2346-2359.

[23] Fu, S.-Y., Feng, X.-Q., Lauke, B. and Mai, Y.-W. Effects of particle size, particle/matrix interface adhesion and particle loading on mechanical properties of particulate-polymer composites, Compos. Part B Eng., 2008, 39, (6), pp 933-961.

[24] Scott, J. and Phillips, D. Carbon fibre composites with rubber toughened matrices, J. Mater. Sci., 1975, 10(4), pp 551-562.

[25] Dadfar, M.R. and Ghadami, F. Effect of rubber modification on fracture toughness properties of glass reinforced hot cured epoxy composites, Mater. Des., 2013, 47, pp 16-20.

[26] Tsai, J.-L., Huang, B.-H. and Cheng, Y.-L. Enhancing fracture toughness of glass/epoxy composites by using rubber particles together with silica nanoparticles, J. Compos. Mater., 2009, 43, (25), pp 3107-3123.

[27] Tang, Y., Ye, L., Zhang, D. and Deng, S. Characterization of transverse tensile, interlaminar shear and interlaminate fracture in CF/EP laminates with $10 \mathrm{wt} \%$ and $20 \mathrm{wt} \%$ silica nanoparticles in matrix resins, Compos. Part A Appl. Sci. Manuf., 2011, 42, (12), pp 1943-1950.

[28] Karnati, S.R., Agbo, P. and Zhang, L. Applications of silica nanoparticles in glass/carbon fiber-reinforced epoxy nanocomposite, Compos. Commun., 2020, 17, pp 32-41.

[29] Sprenger, S. Nanosilica-toughened epoxy resins. Polymers, 2020, 12, (8), p 1777.

[30] Kinloch, A., Masania, K., Taylor, A., Sprenger, S. and Egan, D. The fracture of glass-fibre-reinforced epoxy composites using nanoparticle-modified matrices, J. Mater. Sci., 2008, 43, (3), pp 1151-1154.

[31] Zeng, Y., Liu, H.-Y., Mai, Y.-W. and Du, X.-S. Improving interlaminar fracture toughness of carbon fibre/epoxy laminates by incorporation of nano-particles, Compos. Part B Eng., 2012, 43, (1), pp 90-94.

[32] Sprenger, S. Fiber-reinforced composites based on epoxy resins modified with elastomers and surface-modified silica nanoparticles, J. Mater. Sci., 2014, 49, (6), pp 2391-2402.

[33] Sprenger, S. Epoxy resins modified with elastomers and surface-modified silica nanoparticles, Polymer, 2013, 54, (18), pp 4790-4797.

[34] Hsieh, T., Kinloch, A., Masania, K., Lee, J.S., Taylor, A. and Sprenger, S. The toughness of epoxy polymers and fibre composites modified with rubber microparticles and silica nanoparticles, J. Mater. Sci., 2010, 45, (5), pp 1193-1210.

[35] Tsai, S.N., Carolan, D., Sprenger, S. and Taylor, A.C. Fracture and fatigue behaviour of carbon fibre composites with nanoparticle-sized fibres. Compos. Struct., 2019, 217, pp. 143-149. 
[36] van der Heijden, S., Daelemans, L., Meireman, T., De Baere, I., Rahier, H., Van Paepegem, W. and De Clerck, K. Interlaminar toughening of resin transfer molded laminates by electrospun polycaprolactone structures: Effect of the interleave morphology, Compos. Sci. Technol., 2016, 136, pp 10-17.

[37] Del Saz-Orozco, B., Ray, D., Kervennic, A., McGrail,P. and Stanley, W.F. Toughening of carbon fibre/polybenzoxazine composites by incorporating polyethersulfone into the interlaminar region, Mater. Des., 2016, 93, pp 297-303.

[38] Yun, N.G., Won, Y.G. and Kim, S.C. Toughening of epoxy composite by dispersing polysulfone particle to form morphology spectrum, Polym. Bull., 2004, 52, (5), pp 365-372.

[39] Huang, Y., Liu, W., Jiang, Q., Wei, Y. and Qiu, Y. Interlaminar fracture toughness of carbon-fiber-reinforced epoxy composites toughened by poly (phenylene oxide) particles, ACS Appl. Polym. Mater., 2020, 2, (8), pp 3114-3121.

[40] Zhang, J. and Fox, B.L. Manufacturing influence on the delamination fracture behavior of the T800H/3900-2 carbon fiber reinforced polymer composites, Mater. Manuf. Process., 2007, 22, (6), pp 768-772.

[41] Hunt, C., Kratz, J. and Partridge, I.K. Cure path dependency of mode I fracture toughness in thermoplastic particle interleaf toughened prepreg laminates, Compos. Part A Appl. Sci. Manuf., 2016, 87, pp 109-114.

[42] Hojo, M., Matsuda, S., Tanaka, M., Ochiai, S. and Murakami, A. Mode I delamination fatigue properties of interlayertoughened CF/epoxy laminates, Compos. Sci. Technol., 2006, 66, (5), pp 665-675.

[43] Liu, D., Li, G., Li, B., Luan, Y., Ling, H. and Yang, X. In-situ toughened CFRP composites by shear-calender orientation and fiber-bundle filtration of PA microparticles at prepreg interlayer. Composi. Part A Appl. Sci. Manuf., 2016, 84, pp $165-174$.

[44] Turmel, D.-P. and Partridge, I. Heterogeneous phase separation around fibres in epoxy/PEI blends and its effect on composite delamination resistance, Compos. Sci. Technol., 1997, 57, (8), pp 1001-1007.

[45] Hillermeier, R. and Seferis, J. Interlayer toughening of resin transfer molding composites, Compos. Part A Appl. Sci. Manuf., 2001, 32, (5), pp 721-729.

[46] Wu, Z., Yi, X.-S. and Wilkinson, A. Interlaminar fracture toughness of carbon fibre/RTM6-2 composites toughened with thermoplastic-coated fabric reinforcement, Compos. Part B Eng., 2017, 130, pp 192-199.

[47] Bahrami, A., Cordenier, F., Van Velthem, P., Ballout, W., Pardoen, T., Nysten, B. and Bailly, C. Synergistic local toughening of high performance epoxy-matrix composites using blended block copolymer-thermoplastic thin films, Compos. Part A Appl. Sci. Manuf., 2016, 91, pp 398-405.

[48] Wang, W.-T., Yu, H., Potter, K. and Kim, B.C. Effect of the characteristics of nylon microparticles on Mode-I interlaminar fracture toughness of carbon-fibre/epoxy composites, Compos. Part A Appl. Sci. Manuf., 2020, 138, p 106073.

[49] Zhang, D., Ye, L., Deng, S., Zhang, J., Tang, Y. and Chen, Y. CF/EP composite laminates with carbon black and copper chloride for improved electrical conductivity and interlaminar fracture toughness, Compos. Sci. Technol., 2012, 72, (3), pp 412-420.

[50] Quan, D., Urdániz, J.L. and Ivanković, A. Enhancing mode-I and mode-II fracture toughness of epoxy and carbon fibre reinforced epoxy composites using multi-walled carbon nanotubes, Mater. Des., 2018, 143, pp 81-92.

[51] Khan, S.U. and Kim, J.-K. Impact and delamination failure of multiscale carbon nanotube-fiber reinforced polymer composites: a review, Int. J. Aeronaut. Space Sci., 2011, 12, (2), pp 115-133.

[52] Wang, Z., Soutis, C. and Gresil,M. Fracture toughness of hybrid carbon fibre/epoxy enhanced by graphene and carbon nanotubes, Appl. Compos. Mater., 2021, pp 1-15.

[53] Quaresimin, M. and Varley, R.J. Understanding the effect of nano-modifier addition upon the properties of fibre reinforced laminates, Compos. Sci. Technol., 2008, 68, (3-4), pp 718-726.

[54] Ahmadi-Moghadam, B. and Taheri, F. Influence of graphene nanoplatelets on modes I, II and III interlaminar fracture toughness of fiber-reinforced polymer composites, Eng. Fract. Mech., 2015, 143, pp 97-107.

[55] Kostagiannakopoulou, C., Loutas, T., Sotiriadis, G., Markou, A. and Kostopoulos, V. On the interlaminar fracture toughness of carbon fiber composites enhanced with graphene nano-species, Compos. Sci. Technol., 2015, 118, pp 217-225.

[56] Körbelin, J., Kötter, B., Voormann, H., Brandenburg, L., Selz, S. and Fiedler, B. Damage tolerance of few-layer graphene modified CFRP: from thin-to thick-ply laminates, Compos. Sci. Technol., 2021, p 108765.

[57] Zeng, L., Liu, X., Chen, X. and Soutis, C. $\pi-\pi$ interaction between carbon fibre and epoxy resin for interface improvement in composites, Compos. Part B Eng., 2021, p 108983.

[58] Domun, N., Hadavinia, H., Zhang, T., Sainsbury, T., Liaghat, G. and Vahid, S. Improving the fracture toughness and the strength of epoxy using nanomaterials-a review of the current status, Nanoscale, 2015, 7, (23), pp 10294-10329.

[59] Godara, A., Mezzo, L., Luizi, F., Warrier, A., Lomov, S.V., Van Vuure, A.W., Gorbatikh, L., Moldenaers, P. and Verpoest, I. Influence of carbon nanotube reinforcement on the processing and the mechanical behaviour of carbon fiber/epoxy composites, Carbon, 2009, 47, (12), pp 2914-2923.

[60] Seyhan, A.T., Tanoglu, M. and Schulte, K. Mode I and mode II fracture toughness of E-glass non-crimp fabric/carbon nanotube (CNT) modified polymer based composites, Eng. Fract. Mech., 2008, 75, (18), pp 5151-5162.

[61] Jiménez-Suárez, A., Campo, M., Sánchez, M., Romón, C. and Ureña, A. Influence of the functionalization of carbon nanotubes on calendering dispersion effectiveness in a low viscosity resin for VARIM processes, Compos. Part B Eng., 2012, 43, (8), pp 3482-3490.

[62] Karapappas, P., Vavouliotis, A., Tsotra, P., Kostopoulos, V. and Paipetis, A. Enhanced fracture properties of carbon reinforced composites by the addition of multi-wall carbon nanotubes, J. Compos. Mater., 2009, 43, (9), pp 977-985.

[63] Domun, N., Paton, K.R., Blackman, B.R., Kaboglu, C., Vahid, S., Zhang, T., Dear, J.P., Kinloch, A.J. and Hadavinia, H. On the extent of fracture toughness transfer from 1D/2D nanomodified epoxy matrices to glass fibre composites, J. Mater. Sci., 2020, 55, (11), pp 4717-4733. 
[64] Zhu, Y., Bakis, C.E. and Adair, J.H. Effects of carbon nanofiller functionalization and distribution on interlaminar fracture toughness of multi-scale reinforced polymer composites, Carbon, 2012, 50, (3), pp 1316-1331.

[65] Mujika, F., Vargas, G., Ibarretxe, J., De Gracia, J. and Arrese, A. Influence of the modification with MWCNT on the interlaminar fracture properties of long carbon fiber composites, Compos. Part B Eng., 2012, 43, (3), pp 1336-1340.

[66] Kepple, K., Sanborn, G., Lacasse, P., Gruenberg, K. and Ready, W. Improved fracture toughness of carbon fiber composite functionalized with multi walled carbon nanotubes, Carbon, 2008, 46, (15), pp 2026-2033.

[67] Storck, S., Malecki, H., Shah, T. and Zupan, M. Improvements in interlaminar strength: a carbon nanotube approach, Compos. Part B Eng., 2011, 42, (6), pp 1508-1516.

[68] Lomov, S.V., Gorbatikh, L., Kotanjac, Ž., Koissin, V., Houlle, M., Rochez, O., Karahan, M., Mezzo, L. and Verpoest, I. Compressibility of carbon woven fabrics with carbon nanotubes/nanofibres grown on the fibres, Compos. Sci. Technol., 2011, 71, (3), pp 315-325.

[69] Patel, K., Potluri, P., Yousaf, Z. and Wilkinson, A. Multi-scale reinforcement of epoxy composites-use of carbon fibre fabrics coated with an epoxy binder containing MWCNTs for improved interlaminar fracture resistance, Compos. Part B Eng., 2019, 165, p 109-119.

[70] Mirjalili, V., Ramachandramoorthy, R. and Hubert, P. Enhancement of fracture toughness of carbon fiber laminated composites using multi wall carbon nanotubes, Carbon, 2014, 79, pp 413-423.

[71] Quan, D., Mischo, C., Binsfeld, L., Ivankovic, A. and Murphy, N. Fracture behaviour of carbon fibre/epoxy composites interleaved by MWCNT-and graphene nanoplatelet-doped thermoplastic veils, Compos. Struct., 2020, 235, p 111767.

[72] Quan, D., Mischo, C., Li, X., Scarselli, G., Ivanković, A. and Murphy, N. Improving the electrical conductivity and fracture toughness of carbon fibre/epoxy composites by interleaving MWCNT-doped thermoplastic veils, Compos. Sci. Technol., 2019, 182, p 107775.

[73] Ni, X., Furtado, C., Fritz, N.K., Kopp, R., Camanho, P.P. and Wardle, B.L. Interlaminar to intralaminar mode I and II crack bifurcation due to aligned carbon nanotube reinforcement of aerospace-grade advanced composites, Compos. Sci. Technol., 2020, 190, p 108014.

[74] Garcia, E.J., Wardle, B.L. and Hart, A.J. Joining prepreg composite interfaces with aligned carbon nanotubes, Compos. Part A Appl. Sci. Manuf., 2008, 39, (6), pp 1065-1070.

[75] Xin, W., Sarasini, F., Tirillò, J., Bavasso, I., Sbardella, F., Lampani, L. and De Rosa, I. Impact and post-impact properties of multiscale carbon fiber composites interleaved with carbon nanotube sheets, Compos. Part B Eng., 2020, 183, p 107711.

[76] Ou, Y., González, C. and Vilatela, J.J. Interlaminar toughening in structural carbon fiber/epoxy composites interleaved with carbon nanotube veils, Compos. Part A Appl. Sci. Manuf., 2019, 124, p 105477.

[77] Khan, S.U. and Kim, J.-K. Improved interlaminar shear properties of multiscale carbon fiber composites with bucky paper interleaves made from carbon nanofibers, Carbon, 2012, 50, (14), pp 5265-5277.

[78] Liu, L., Shen, L. and Zhou, Y. Improving the interlaminar fracture toughness of carbon/epoxy laminates by directly incorporating with porous carbon nanotube buckypaper, J. Reinf. Plast. Compos., 2016, 35, (2), pp 165-176.

[79] Browning, C.E. and Schwartz, H.S. Delamination resistant composite concepts, Composite Materials: Testing and Design (Seventh Conference), ASTM International, 1986.

[80] Green, A., Bashford, D. and Bowyer, W. Assessment of chopped strand mat GRP lamination for the construction of damage resistant ship hull structures, Composites, 1982, 13, (4), pp 401-405.

[81] Nash, N., Ray, D., Young, T. and Stanley, W. The influence of hydrothermal conditioning on the Mode-I, thermal and flexural properties of Carbon/Benzoxazine composites with a thermoplastic toughening interlayer, Compos. Part A Appl. Sci. Manuf., 2015, 76, pp 135-144.

[82] O'Donovan, K., Ray, D. and McCarthy, M.A. Toughening effects of interleaved nylon veils on glass fabric/low-styreneemission unsaturated polyester resin composites, J. Appl. Polym. Sci., 2015, 132, (7).

[83] Fitzmaurice, K., Ray, D. and Mccarthy, M.A. PET interleaving veils for improved fracture toughness of glass fibre/lowstyrene-emission unsaturated polyester resin composites, J. Appl. Polym. Sci., 2016, 133, (3).

[84] Zhang, J., Lin, T. and Wang, X. Electrospun nanofibre toughened carbon/epoxy composites: Effects of polyetherketone cardo (PEK-C) nanofibre diameter and interlayer thickness, Compos. Sci. Technol., 2010, 70, (11), pp 1660-1666.

[85] Li, G., Li, P., Zhang, C., Yu, Y., Liu, H., Zhang, S., Jia, X., Yang, X., Xue, Z. and Ryu, S. Inhomogeneous toughening of carbon fiber/epoxy composite using electrospun polysulfone nanofibrous membranes by in situ phase separation, Compos. Sci. Technol., 2008, 68, (3-4), pp 987-994.

[86] Shin, J.H., Anders, M., Kim, D., Jin, B.C. and Nutt, S. Effects of post-infusion dwell on vacuum infusion of thermoset composites toughened by thermoplastic interlaminar veils, J. Compos. Mater., 2020, p 0021998320971342.

[87] Girardy, H. and Beraud, J.-M. HiTape (R) dry preform technology-an efficient composite automation technology for primary aircraft structures, Sampe J., 2015, 51, (4), pp 7-15.

[88] Albrecht, W., Fuchs, H. and Kittelmann, W. Nonwoven Fabrics: Raw Materials, Manufacture, Applications, Characteristics, Testing Processes, John Wiley \& Sons, 2006.

[89] TFP veil products for composite materials. 22.02.2021]; Available from: https://www.tfpglobal.com/products/ compositematerials.

[90] Quan, D., Bologna, F., Scarselli, G., Ivankovic, A. and Murphy, N. Interlaminar fracture toughness of aerospace-grade carbon fibre reinforced plastics interleaved with thermoplastic veils, Compos. Part A Appl. Sci. Manuf., 2020, 128, p 105642 .

[91] İnal, O., Akbolat, M.Ç., Soutis, C. and Katnam, K.B. Toughening mechanisms in cost-effective carbon-epoxy laminates with thermoplastic veils: Mode-I and in-situ SEM fracture characterization, Int. J. Lightweight Mater. Manuf., 2021, 4, (1), pp 50-61. 
[92] Ramirez, V.A., Hogg, P.J. and Sampson, W.W. The influence of the nonwoven veil architectures on interlaminar fracture toughness of interleaved composites, Compos. Sci. Technol., 2015, 110, pp 103-110.

[93] Beylergil, B., Tanoğlu, M. and Aktaş, E. Effect of polyamide-6, 6 (PA 66) nonwoven veils on the mechanical performance of carbon fiber/epoxy composites, Compos. Struct., 2018, 194, pp 21-35.

[94] García-Rodríguez, S., Costa, J., Rankin, K., Boardman, R., Singery, V. and Mayugo, J. Interleaving light veils to minimise the trade-off between mode-I interlaminar fracture toughness and in-plane properties, Compos. Part A Appl. Sci. Manuf., 2020, 128, p 105659.

[95] Kuwata, M. and Hogg, P. Interlaminar toughnes s of interleaved CFRP using non-woven veils: Part 1. Mode-I testing, Compos. Part A Appl. Sci. Manuf., 2011, 42, (10), pp 1551-1559.

[96] Lee, S.-H., Lee, J.-H., Cheong, S.-K. and Noguchi, H. A toughening and strengthening technique of hybrid composites with non-woven tissue, J. Mater. Process. Technol., 2008, 207, (1-3), pp 21-29.

[97] Arouche, M.M., de Freitas, S.T. and de Barros, S. On the influence of glass fiber mat on the mixed-mode fracture of composite-to-metal bonded joints, Compos. Struct., 2021, 256, p 113109.

[98] Beylergil, B., Tanoglu, M. and Aktas, E. Mode-I fracture toughness of carbon fiber/epoxy composites interleaved by aramid nonwoven veils, Steel Compos. Struct., 2019, 31, (2), pp 113-123.

[99] Sohn, M.-S. and Hu, X.-Z. Mode II delamination toughness of carbon-fibre/epoxy composites with chopped Kevlar fibre reinforcement, Compos. Sci. Technol., 1994, 52, (3), pp 439-448.

[100] Kuwata, M. and Hogg, P. Interlaminar toughness of interleaved CFRP using non-woven veils: Part 2. Mode-II testing, Compos. Part A Appl. Sci. Manuf., 2011, 42, (10), pp 1560-1570.

[101] Del Saz-Orozco, B., Ray, D. and Stanley, W.F. Effect of thermoplastic veils on interlaminar fracture toughness of a glass fiber/vinyl ester composite, Polym. Compos., 2017, 38, (11), pp 2501-2508.

[102] Quan, D., Bologna, F., Scarselli, G., Ivanković, A. and Murphy, N. Mode-II fracture behaviour of aerospace-grade carbon fibre/epoxy composites interleaved with thermoplastic veils, Compos. Sci. Technol., 2020, 191, p 108065.

[103] Walker, L., Sohn, M.-S. and Hu, X.-Z. Improving impact resistance of carbon-fibre composites through interlaminar reinforcement, Compos. Part A Appl. Sci. Manuf., 2002, 33, (6), pp 893-902.

[104] Hogg, P.J. Toughening of thermosetting composites with thermoplastic fibres, Mater. Sci. Eng. A, 2005, 412, (1-2), pp 97-103.

[105] Nash, N., Young, T. and Stanley, W. An investigation of the damage tolerance of carbon/Benzoxazine composites with a thermoplastic toughening interlayer, Compos. Struct., 2016, 147, pp 25-32.

[106] Davies, G. and Zhang, X. Impact damage prediction in carbon composite structures, Int. J. Impact Eng., 1995, 16, (1), pp 149-170.

[107] Jiang, S., Chen, Y., Duan, G., Mei, C., Greiner, A. and Agarwal, S. Electrospun nanofiber reinforced composites: a review, Polym. Chem., 2018, 9, (20), pp 2685-2720.

[108] Wang, G., Yu, D., Kelkar, A.D. and Zhang, L. Electrospun nanofiber: Emerging reinforcing filler in polymer matrix composite materials, Prog. Polym. Sci., 2017, 75, pp 73-107.

[109] Zucchelli, A., Focarete, M.L., Gualandi, C. and Ramakrishna, S. Electrospun nanofibers for enhancing structural performance of composite materials, Polym. Adv. Technol., 2011, 22, (3), pp 339-349.

[110] Li, D. and Xia, Y. Electrospinning of nanofibers: reinventing the wheel? Adv. Mater., 2004. 16, (14), pp 1151-1170.

[111] Dzenis, Y.A. and Reneker, D.H. Delamination resistant composites prepared by small diameter fiber reinforcement at ply interfaces, 2001, Google Patents.

[112] Palazzetti, R. and Zucchelli, A. Electrospun nanofibers as reinforcement for composite laminates materials-a review, Compos. Struct., 2017, 182, pp 711-727.

[113] Bilge, K., Ozden-Yenigun, E., Simsek, E., Menceloglu, Y. and Papila, M. Structural composites hybridized with epoxy compatible polymer/MWCNT nanofibrous interlayers, Compos. Sci. Technol., 2012, 72, (14), pp 1639-1645.

[114] Bilge, K., Venkataraman, S., Menceloglu, Y. and Papila, M. Global and local nanofibrous interlayer toughened composites for higher in-plane strength, Compos. Part A Appl. Sci. Manuf., 2014, 58, pp 73-76.

[115] Daelemans, L., van der Heijden, S., De Baere, I., Rahier, H., Van Paepegem, W., and De Clerck, K. Damage-resistant composites using electrospun nanofibers: a multiscale analysis of the toughening mechanisms, ACS Appl. Mater. Interfaces, 2016, 8, (18), pp 11806-11818.

[116] van der Heijden, S., Daelemans, L., De Schoenmaker, B., De Baere, I., Rahier, H., Van Paepegem, W. and De Clerck, K. Interlaminar toughening of resin transfer moulded glass fibre epoxy laminates by polycaprolactone electrospun nanofibres, Compos. Sci. Technol., 2014, 104, pp 66-73.

[117] De Schoenmaker, B., Van der Heijden, S., De Baere, I., Van Paepegem, W. and De Clerck, K. Effect of electrospun polyamide 6 nanofibres on the mechanical properties of a glass fibre/epoxy composite, Polym. Test., 2013, 32, (8), pp 1495-1501.

[118] Daelemans, L., van der Heijden, S., De Baere, I., Rahier, H., Van Paepegem, W. and De Clerck, K. Nanofibre bridging as a toughening mechanism in carbon/epoxy composite laminates interleaved with electrospun polyamide nanofibrous veils, Compos. Sci. Technol., 2015, 117, pp 244-256.

[119] Beylergil, B., Tanoğlu, M. and Aktaş, E. Modification of carbon fibre/epoxy composites by polyvinyl alcohol (PVA) based electrospun nanofibres, Adv. Compos. Lett., 2016, 25, (3), pp. 69-76.

[120] Beylergil, B., Tanoğlu, M. and Aktaş, E. Enhancement of interlaminar fracture toughness of carbon fiber-epoxy composites using polyamide-6, 6 electrospun nanofibers, J. Appl. Polymer Sci., 2017, 134, (35), 45244.

[121] Liu, L., Huang, Z.-M., He, C. and Han, X. Mechanical performance of laminated composites incorporated with nanofibrous membranes, Mater. Sci. Eng. A, 2006, 435, pp 309-317. 
[122] Chen, Q., Zhao, Y., Zhou, Z., Rahman, A., Wu, X.-F., Wu, W., Xu, T. and Fong, H. Fabrication and mechanical properties of hybrid multi-scale epoxy composites reinforced with conventional carbon fiber fabrics surface-attached with electrospun carbon nanofiber mats, Compos. Part B Eng., 2013, 44, (1), pp 1-7.

[123] Saghafi, H., Zucchelli, A., Palazzetti, R. and Minak, G. The effect of interleaved composite nanofibrous mats on delamination behavior of polymeric composite materials, Compos. Struct., 2014, 109, pp 41-47.

[124] Daelemans, L., Kizildag, N., Van Paepegem, W., D’hooge, D.R. and De Clerck, K. Interdiffusing core-shell nanofiber interleaved composites for excellent Mode I and Mode II delamination resistance, Compos. Sci. Technol., 2019, 175, pp 143-150.

[125] Li, P., Liu, D., Zhu, B., Li, B., Jia, X., Wang, L., Li, G. and Yang, X. Synchronous effects of multiscale reinforced and toughened CFRP composites by MWNTs-EP/PSF hybrid nanofibers with preferred orientation, Compos. Part A Appl. Sci. Manuf., 2015, 68, pp 72-80.

[126] Daelemans, L., van der Heijden, S., De Baere, I., Rahier, H., Van Paepegem, W. and De Clerck, K. Using aligned nanofibres for identifying the toughening micromechanisms in nanofibre interleaved laminates, Compos. Sci. Technol., 2016, 124, pp 17-26.

[127] Tzetzis, D., Hogg, P. and Jogia, M. Double cantilever beam Mode-I testing for vacuum infused repairs of GFRP, J. Adhes. Sci. Technol., 2003, 17, (3), pp 309-328.

[128] Tzetzis, D. and Hogg, P. Bondline toughening of vacuum infused composite repairs, Compos. Part A Appl. Sci. Manuf., 2006, 37, (9), pp 1239-1251.

[129] Ravindran, A.R., Ladani, R.B., Wu, S., Kinloch, A.J., Wang, C.H. and Mouritz, A.P. Multi-scale toughening of epoxy composites via electric field alignment of carbon nanofibres and short carbon fibres, Compos. Sci. Technol., 2018, 167, pp $115-125$.

[130] Ladani, R.B., Wu, S., Kinloch, A.J., Ghorbani, K., Zhang, J., Mouritz, A.P. and Wang, C.H. Improving the toughness and electrical conductivity of epoxy nanocomposites by using aligned carbon nanofibres, Compos. Sci. Technol., 2015, 117, pp $146-158$.

[131] Huang, B.-Z., Hu, X.-Z. and Liu, J. Modelling of inter-laminar toughening from chopped Kevlar fibers, Compos. Sci. Technol., 2004, 64, (13-14), pp 2165-2175.

[132] Huang, B.-Z. and Zhao, L.-J. Bridging and toughening of short fibers in SMC and parametric optimum, Compos. Part B Eng., 2012, 43, (8), pp 3146-3152.

[133] Teklal, F., Djebbar, A., Allaoui, S., Hivet, G., Joliff, Y. and Kacimi, B. A review of analytical models to describe pull-out behavior-Fiber/matrix adhesion, Compos. Struct., 2018, 201, pp 791-815.

[134] Sohn, M.-S. and Hu, X.-Z. Delamination behavior of carbon fiber/epoxy composite laminates with short fiber reinforcement, Scripta Metallurgica et Materialia;(United States), 1994, 30, (11).

[135] Daelemans, L., van der Heijden, S., De Baere, I., Rahier, H., Van Paepegem, W. and De Clerck, K. Improved fatigue delamination behaviour of composite laminates with electrospun thermoplastic nanofibrous interleaves using the Central Cut-Ply method, Compos. Part A Appl. Sci. Manuf., 2017, 94, pp 10-20.

[136] Nash, N., Young, T. and Stanley, W. The influence of a thermoplastic toughening interlayer and hydrothermal conditioning on the Mode-II interlaminar fracture toughness of Carbon/Benzoxazine composites, Compos. Part A Appl. Sci. Manuf., 2016, 81, pp 111-120.

[137] Nash, N., Young, T. and Stanley, W. The reversibility of Mode-I and-II interlaminar fracture toughness after hydrothermal aging of Carbon/Benzoxazine composites with a thermoplastic toughening interlayer, Compos. Struct., 2016, 152, pp 558567.

[138] Wang, J., Ma, C., Chen, G. and Dai, P. Interlaminar fracture toughness and conductivity of carbon fiber/epoxy resin composite laminate modified by carbon black-loaded polypropylene non-woven fabric interleaves, Compos. Struct., 2020, 234, p 111649.

[139] Quan, D., Deegan, B., Alderliesten, R., Dransfeld, C., Murphy, N., Ivanković, A. and Benedictus, R. The influence of interlayer/epoxy adhesion on the mode-I and mode-II fracture response of carbon fibre/epoxy composites interleaved with thermoplastic veils, Mater. Des., 2020, p 108781.

[140] Quan, D., Deegan, B., Binsfeld, L., Li, X., Atkinson, J., Ivanković, A. and Murphy, N. Effect of interlaying UV-irradiated PEEK fibres on the mechanical, impact and fracture response of aerospace-grade carbon fibre/epoxy composites, Compos. Part B Eng., 2020, 191, p 107923.

[141] Quan, D., Alderliesten, R., Dransfeld, C., Murphy, N., Ivanković, A. and Benedictus, R. Enhancing the fracture toughness of carbon fibre/epoxy composites by interleaving hybrid meltable/non-meltable thermoplastic veils, Compos. Struct., 2020, 252, p 112699.

[142] Wong, D.W., Lin, L., McGrail, P.T., Peijs, T. and Hogg, P.J. Improved fracture toughness of carbon fibre/epoxy composite laminates using dissolvable thermoplastic fibres, Compos. Part A Appl. Sci. Manuf., 2010, 41, (6), pp 759-767.

[143] Zhang, H., Bharti, A., Li, Z., Du, S., Bilotti, E. and Peijs, T. Localized toughening of carbon/epoxy laminates using dissolvable thermoplastic interleaves and electrospun fibres, Compos. Part A Appl. Sci. Manuf., 2015, 79, pp 116-126.

[144] Zheng, N., Huang, Y., Liu, H.-Y., Gao, J. and Mai, Y.-W. Improvement of interlaminar fracture toughness in carbon fiber/epoxy composites with carbon nanotubes/polysulfone interleaves, Compos. Sci. Technol., 2017, 140, pp 8-15.

[145] Bradley, W.L. Relationship of matrix toughness to interlaminar fracture toughness, Composite Materials Series, 1989, Elsevier. pp 159-187.

[146] Siddiqui, N.A., Woo, R.S., Kim, J.-K., Leung, C.C. and Munir, A. Mode I interlaminar fracture behavior and mechanical properties of CFRPs with nanoclay-filled epoxy matrix, Compos. Part A Appl. Ssci. Manuf. 2007, 38, (2), pp 449-460. 
[147] Klingler, A., Bajpai, A. and Wetzel, B. The effect of block copolymer and core-shell rubber hybrid toughening on morphology and fracture of epoxy-based fibre reinforced composites, Eng. Fract. Mech., 2018, 203, pp 81-101.

[148] Ngah, S.A. and Taylor, A.C. Toughening performance of glass fibre composites with core-shell rubber and silica nanoparticle modified matrices, Compos. Part A Appl. Sci. Manuf., 2016, 80, pp 292-303.

[149] Stevanovic, D., Kalyanasundaram, S., Lowe, A. and Jar, P.-Y. Mode I and mode II delamination properties of glass/vinylester composite toughened by particulate modified interlayers, Compos. Sci. Technol., 2003, 63, (13), pp 1949-1964.

[150] Cooper, V., Ivankovic, A., Karac, A., McAuliffe, D. and Murphy, N. Effects of bond gap thickness on the fracture of nano-toughened epoxy adhesive joints, Polymer, 2012, 53, (24), pp 5540-5553.

[151] Sela, N., Ishai, O. and Banks-Sills, L. The effect of adhesive thickness on interlaminar fracture toughness of interleaved CFRP specimens, Composites, 1989, 20, (3), pp 257-264.

[152] Aksoy, A. and Carlsson, L. Interlaminar shear fracture of interleaved graphite/epoxy composites, Compos. Sci. Technol., 1992, 43, (1), pp 55-69.

[153] Groleau, M., Shi, Y.-B., Yee, A., Bertram, J., Sue, H. and Yang, P. Mode II fracture of composites interlayered with nylon particles, Compos, Sci. Technol., 1996, 56, (11), pp 1223-1240.

[154] Shen, L., Liu, L., Zhou, Y. and Wu, Z. Thickness effect of carbon nanotube interleaves on free-edge delamination and ultimate strength within a symmetric composite laminate, Compos. Part A Appl. Sci. Manuf., 2020, 132, p 105828.

[155] Beckermann, G.W. and Pickering, K.L. Mode I and Mode II interlaminar fracture toughness of composite laminates interleaved with electrospun nanofibre veils, Compos. Part A Appl. Sci. Manuf., 2015, 72, pp 11-21.

[156] Ramji, A., Xu, Y., Yasaee, M., Grasso, M. and Webb, P. Delamination migration in CFRP laminates under mode I loading, Compos. Sci. Technol., 2020, 190, p 108067.

[157] Beylergil, B., Tanoğlu, M. and Aktaş, E. Experimental and statistical analysis of carbon fiber/epoxy composites interleaved with nylon 6, 6 nonwoven fabric interlayers, J. Compos. Mater., 2020, 54, (27), pp 4173-4184.

[158] Brugo, T. and Palazzetti, R. The effect of thickness of Nylon 6, 6 nanofibrous mat on Modes I-II fracture mechanics of UD and woven composite laminates, Compos. Struct., 2016, 154, pp 172-178.

[159] Yasaee, M., Bond, I., Trask, R. and Greenhalgh, E. Mode I interfacial toughening through discontinuous interleaves for damage suppression and control, Compos. Part A Appl. Sci. Manuf., 2012, 43, (1), pp 198-207.

[160] Yasaee, M., Bond, I., Trask, R. and Greenhalgh, E. Mode II interfacial toughening through discontinuous interleaves for damage suppression and control, Compos. Part A Appl. Sci. Manuf., 2012, 43, (1), pp 121-128.

[161] Arnold, M., Henne, M., Bender, K. and Drechsler, K. The influence of various kinds of PA12 interlayer on the interlaminar toughness of carbon fiber-reinforced epoxy composites, Polym. Compos., 2015, 36, (7), pp 1249-1257.

[162] Chen, G., Zhang, J., Liu, G., Chen, P. and Guo, M. Controlling the crack propagation path of the veil interleaved composite by fusion-bonded dots, Polymers, 2019, 11, (8), p 1260.

[163] Sun, Z., Hu, X., Shi, S., Guo, X., Zhang, Y. and Chen, H. Edge delamination and residual properties of drilled carbon fiber composites with and without short-aramid-fiber interleaf, Appl. Compos. Mater., 2016, 23, (5), pp 973-985.

[164] Nettles, A.T. and Scharber, L. The Influence of GI and GII on the compression after impact strength of carbon fiber/epoxy laminates, J. Compos. Mater., 2018, 52, (8), pp 991-1003.

[165] Zheng, N., Liu, H.-Y., Gao, J. and Mai, Y.-W. Synergetic improvement of interlaminar fracture energy in carbon fiber/epoxy composites with nylon nanofiber/polycaprolactone blend interleaves, Compos. Part B Eng., 2019, 171, pp 320-328.

[166] Hamer, S., Leibovich, H., Green, A., Avrahami, R., Zussman, E., Siegmann, A. and Sherman, D. Mode I and Mode II fracture energy of MWCNT reinforced nanofibrilmats interleaved carbon/epoxy laminates, Compos. Sci. Technol., 2014, 90, pp 48-56.

[167] Mohammadi, R., Najafabadi, M.A., Saghafi, H., Saeedifar, M. and Zarouchas, D. A quantitative assessment of the damage mechanisms of CFRP laminates interleaved by PA66 electrospun nanofibers using acoustic emission, Compos. Struct., 2021, 258, p 113395.

[168] Elias, V.A.R., Effect of nonwoven veil architectures on interlaminar fracture toughness of interleaved composites, The University of Manchester, 2016, UK.

[169] Kuwata, M. Mechanisms of interlaminar fracture toughness using non-woven veils as interleaf materials, 2010.

[170] Guo, M., Yi, X., Liu, G. and Liu, L. Simultaneously increasing the electrical conductivity and fracture toughness of carbonfiber composites by using silver nanowires-loaded interleaves, Compos. Sci. Technol., 2014, 97, pp 27-33.

[171] Guo, M., Yi, X., Rudd, C. and Liu, X. Preparation of highly electrically conductive carbon-fiber composites with high interlaminar fracture toughness by using silver-plated interleaves, Compos. Sci. Technol., 2019, 176, pp 29-36.

[172] Lee, S.-H., Kim, H., Hang, S. and Cheong, S.-K. Interlaminar fracture toughness of composite laminates with CNTenhanced nonwoven carbon tissue interleave, Compos. Sci. Technol., 2012, 73, pp 1-8.

[173] Gouda, P.S., Chatterjee, V., Barhai, P., Jawali, D., Rahatekar, S. and Wisnom, M. Improved fracture toughness in carbon fibre epoxy composite through novel pre-preg coating method using epoxy terminated butadiene nitrile rubber, Mater. Des. (1980-2015), 2014, 62, pp 320-326.

[174] Gouda, P.S., Williams, J.D., Yasaee, M., Chatterjee, V., Jawali, D., Rahatekar, S.S. and Wisnom, M.R. Drawdown prepreg coating method using epoxy terminated butadiene nitrile rubber to improve fracture toughness of glass epoxy composites, J. Compos. Mater., 2016, 50, (7), pp 873-884.

[175] Sprenger, S., Kothmann, M.H. and Altstaedt, V. Carbon fiber-reinforced composites using an epoxy resin matrix modified with reactive liquid rubber and silica nanoparticles, Compos. Sci. Technol., 2014, 105, pp 86-95.

[176] Sue, H.-J., Jones, R. and Garcia-Meitin, E. Fracture behaviour of model toughened composites under Mode I and Mode II delaminations, J. Mater. Sci., 1993, 28, (23), pp 6381-6391. 
[177] Ozdemir, N.G., Zhang, T., Hadavinia, H., Aspin, I. and Scarpa, F. Glass fibre reinforced polymer composites toughened with acrylonitrile butadiene nanorubber. Compos. Part B Eng., 2016, 88, pp 182-188.

[178] Ravindran, A.R., Ladani, R.B., Wang, C.H. and Mouritz, A.P. Hierarchical mode I and mode II interlaminar toughening of Z-pinned composites using 1D and 2D carbon nanofillers, Compos. Part A Appl. Sci. Manuf., 2019, 124, p 105470.

[179] Srivastava, V.K., Gries, T., Veit, D., Quadflieg, T., Mohr, B. and Kolloch, M. Effect of nanomaterial on mode I and mode II interlaminar fracture toughness of woven carbon fabric reinforced polymer composites, Eng. Fract. Mech., 2017, 180, pp 73-86.

[180] Arai, M., Noro, Y., Sugimoto, K.-i. and Endo, M. Mode I and mode II interlaminar fracture toughness of CFRP laminates toughened by carbon nanofiber interlayer, Compos. Sci. Technol., 2008, 68, (2), pp 516-525.

[181] Eskizeybek, V., Yar, A. and Avc1, A. CNT-PAN hybrid nanofibrous mat interleaved carbon/epoxy laminates with improved Mode I interlaminar fracture toughness, Compos. Sci. Technol., 2018, 157, pp 30-39.

[182] Varley, R.J. and Parn, G.P. Thermally activated healing in a mendable resin using a non woven EMAA fabric, Compos. Sci. Technol., 2012, 72, (3), pp 453-460.

[183] Gao, Y., Liu, L., Wu, Z. and Zhong, Z. Toughening and self-healing fiber-reinforced polymer composites using carbon nanotube modified poly (ethylene-co-methacrylic acid) sandwich membrane, Compos. Part A Appl. Sci. Manuf., 2019, 124, p 105510.

[184] Kishi, H., Kuwata, M., Matsuda, S., Asami, T. and Murakami, A. Damping properties of thermoplastic-elastomer interleaved carbon fiber-reinforced epoxy composites, Compos. Sci. Technol., 2004, 64, (16), pp 2517-2523.

[185] Ni, N., Wen, Y., He, D., Yi, X., Zhao, Z. and Xu, Y. Synchronous improvement of loss factors and storage modulus of structural damping composite with functionalized polyamide nonwoven fabrics, Mater. Des., 2016, 94, pp 377-383.

[186] Brown, S., Robert, C., Koutsos, V. and Ray, D. Methods of modifying through-thickness electrical conductivity of CFRP for use in structural health monitoring, and its effect on mechanical properties-a review, Compos. Part A Appl. Sci. Manuf., 2020, 133, p 105885.

[187] Barjasteh, E., Sutanto, C., Reddy, T. and Vinh, J. A graphene/graphite-based conductive polyamide 12 interlayer for increasing the fracture toughness and conductivity of carbon-fiber composites, J. Compos. Mater., 2017, 51, (20), pp 2879-2887.

[188] Knoll, J., Riecken, B., Kosmann, N., Chandrasekaran, S., Schulte, K. and Fiedler, B. The effect of carbon nanoparticles on the fatigue performance of carbon fibre reinforced epoxy, Compos. Part A Appl. Sci. Manuf., 2014, 67, pp $233-240$.

[189] Böger, L., Sumfleth, J., Hedemann, H. and Schulte, K. Improvement of fatigue life by incorporation of nanoparticles in glass fibre reinforced epoxy, Compos. Part A Appl. Sci. Manuf., 2010, 41, (10), pp 1419-1424.

[190] Manjunatha, C., Taylor, A., Kinloch, A. and Sprenger, S. The tensile fatigue behaviour of a silica nanoparticle-modified glass fibre reinforced epoxy composite, Compos. Sci. Technol., 2010, 70, (1), pp 193-199.

[191] Hsieh, T., Kinloch, A., Taylor, A. and Kinloch, I. The effect of carbon nanotubes on the fracture toughness and fatigue performance of a thermosetting epoxy polymer, J. Mater. Sci., 2011, 46, (23), pp 7525-7535.

[192] Zhou, Y., Pervin, F., Jeelani, S. and Mallick, P. Improvement in mechanical properties of carbon fabric-epoxy composite using carbon nanofibers, J. Mater. Process. Technol., 2008, 198, (1-3), pp 445-453.

[193] Fenner, J.S. and Daniel, I.M. Hybrid nanoreinforced carbon/epoxy composites for enhanced damage tolerance and fatigue life, Compos. Part A Appl. Sci. Manuf., 2014, 65, pp 47-56.

[194] Brugo, T., Minak, G., Zucchelli, A., Yan, X.T., Belcari, J., Saghafi, H. and Palazzetti, R. Study on Mode I fatigue behaviour of Nylon 6, 6 nanoreinforced CFRP laminates, Compos. Struct., 2017, 164, pp 51-57.

[195] Özden-Yenigün, E., Bilge, K., Sünbüloğlu, E., Bozdağ, E. and Papila, M. High strain rate response of nanofiber interlayered structural composites, Compos. Struct., 2017, 168, pp 47-55.

[196] Landowski, M., Strugała, G., Budzik, M. and Imielińska, K. Impact damage in SiO2 nanoparticle enhanced epoxy-Carbon fibre composites, Compos. Part B Eng., 2017, 113, pp 91-99.

[197] McGrail, P. and Jenkins, S. Some aspects of interlaminar toughening: reactively terminated thermoplastic particles in thermoset composites, Polymer, 1993, 34, (4), pp 677-683.

[198] Xu, F., Du, X.-S., Liu, H.-Y., Guo, W.-G. and Mai, Y.-W. Temperature effect on nano-rubber toughening in epoxy and epoxy/carbon fiber laminated composites, Compos. Part B Eng., 2016, 95, pp 423-432.

[199] Khan, S.U., Iqbal, K., Munir, A. and Kim, J.-K. Quasi-static and impact fracture behaviors of CFRPs with nanoclay-filled epoxy matrix, Compos. Part A Appl. Sci. Manuf., 2011, 42, (3), pp 253-264.

[200] Tsotsis, T.K. Interlayer toughening of composite materials, Polym. Compos., 2009, 30, (1), pp 70-86.

[201] Kwon, D.-J., Shin, P.-S., Kim, J.-H., Baek, Y.-M., Park, H.-S., DeVries, K.L. and Park, J.-M. Interfacial properties and thermal aging of glass fiber/epoxy composites reinforced with $\mathrm{SiC}$ and $\mathrm{SiO} 2$ nanoparticles, Compos. Part B Eng., 2017, 130, pp 46-53.

[202] Bray, D., Dittanet, P., Guild, F., Kinloch, A., Masania, K., Pearson, R. and Taylor, A. The modelling of the toughening of epoxy polymers via silica nanoparticles: The effects of volume fraction and particle size, Polymer, 2013, 54, (26), pp 7022-7032.

[203] Jones, R., Kinloch, A.J., Michopoulos, J.G., Brunner, A.J. and Phan, N. Delamination growth in polymer-matrix fibre composites and the use of fracture mechanics data for material characterisation and life prediction, Compos. Struct., 2017, 180, pp 316-333.

Cite this article: İnal O., Katnam K.B., Potluri P. and Soutis C. (2022). Progress in interlaminar toughening of aerospace polymer composites using particles and non-woven veils. The Aeronautical Journal, 126, 222-248. https://doi.org/10.1017/aer.2021.95 